\title{
Analysis of the dynamic flexural behaviour of composite beams at low temperature
}

\author{
S. Sánchez-Sáez, E. Barbero *, C. Navarro \\ Department of Continuum Mechanics and Structural Analysis, University Carlos III of Madrid, Avda. de la Universidad 30, 28911 Leganés, Madrid, Spain
}

\begin{abstract}
In this study, the dynamic flexural behaviour at low temperatures of beams of three carbon/epoxy laminates is evaluated, analysing the influence of temperature on the mechanical strength, stiffness and absorbed energy until failure. Three point bending tests were per formed under dynamic conditions at three different temperatures $\left(20^{\circ} \mathrm{C}, \quad 60{ }^{\circ} \mathrm{C}\right.$ and $\left.\quad 150{ }^{\circ} \mathrm{C}\right)$, and the results were compared with those found under static conditions at the same temperatures. Both the mechanical strength and the absorbed energy decreased when the tem perature diminished in all the laminates. No significant influence of temperature was noted on the effective flexural modulus. Two ana lytical models, using the classical laminated theory and the first order shear deformation laminate theory, and a numerical model were used to analyse the experimental results of the tests. The models allowed to ensure the use of the equations, which do not consider inertia forces, to calculate the test parameters, and they provided the specimen support span to neglect shear effects. They served also to deter mine the origin of the noise present in the load measured in the dynamic tests.
\end{abstract}

Keywords: A. Carbon fibres; B. Mechanical properties; C. Laminates; B. Low temperature properties; D. Dynamic bending test

\section{Introduction}

Some mechanical and structural elements, such as helicopter blades, robot arms, transmission axes, turbine blades, may be modelled, at least in a preliminary design, as beams subjected to loads that originate mainly bending moments. Laminate composites are widely used to manufacture such elements because of their high specific strength and stiffness, excellent fatigue strength, good corrosion behaviour, and low thermal conductivity. Therefore, to design these components, it is necessary to know the behaviour of the laminate composites when they are subjected to bending moments [1].

These elements may also be subjected to low temperatures in service; for example, the structure of an airplane in flight undergoes temperatures as low as $-60^{\circ} \mathrm{C}$ and a

\footnotetext{
* Corresponding author. Tel.: +349162499 65; fax: +34916249430.

E mail address: ebarbero@ing.uc3m.es (E. Barbero).
}

satellite or a cryogenic tank may be exposed to temperatures below $-150^{\circ} \mathrm{C}$. Changes in the structure and mechanical properties of composite materials may occur under such conditions. As the temperature falls below the stress-free temperature of the laminate, residual stresses develop in the material. When these stresses become large enough, microcracks and/or delamination may appear [2]. Several authors have worked on the mechanical behaviour of composite materials at low temperature, studying this behaviour in elastic vibrations or its mechanical stiffness and strength. Reed and Golda [3] reviewed the effect of low temperature on the static mechanical properties, both in tension and compression, of unidirectional composites reinforced with fibres of boron, alumina, aramid, S-glass, E-glass and carbon. The results available reveal no definable trends regarding the influence of low temperature on the mechanical behaviour of composite materials. For example, low temperatures may result in an increase, a decrease or a minimal change in the tensile strength [3 5$]$. 


\begin{tabular}{|c|c|c|}
\hline \multicolumn{3}{|l|}{ Nomenclature } \\
\hline $\begin{array}{l}\text { 1-2-3 axis principal material coordinate system } \\
x y z \text { axis global laminate coordinate system }\end{array}$ & $t_{c}$ & $\begin{array}{l}\text { first natural period of vibration of the beam } \\
\text { (s) }\end{array}$ \\
\hline \multirow{2}{*}{$\begin{array}{l}A \quad \text { beam cross-sectional area }\left(\mathrm{m}^{2}\right) \\
A_{0}, A_{n}, B_{n} \text { constants of the Fourier series of the experi- } \\
\quad \text { mental load recorded in the tests }\end{array}$} & $w(x, t)$ & dynamic deflection of the beam calculated by \\
\hline & & $\begin{array}{l}\text { the analytical model at point } x \text { in the instant } \\
\text { of time } t(\mathrm{~m})\end{array}$ \\
\hline \multirow{3}{*}{$\begin{array}{ll}a_{55} & \text { element } 55 \text { of laminate shear compliance ma- } \\
& \text { trix }(\mathrm{m} / \mathrm{N}) \\
\mathrm{AE} & \text { absorbed energy until failure }(\mathrm{J}) \\
B & \text { laminate width }(\mathrm{m})\end{array}$} & $w_{\text {max. st }}^{\mathrm{L}}$ & $\begin{array}{l}\text { maximum static deflection of the beam calcu- } \\
\text { lated by the classical laminated theory }(\mathrm{m})\end{array}$ \\
\hline & $w_{\text {max. d }}^{\mathrm{L}}$ & maximum dynamic deflection of $\mathrm{tl}$ \\
\hline & & latec \\
\hline \multirow{2}{*}{$\begin{array}{l}C_{\mathrm{m}}, D_{\mathrm{m}} \text { integration constants in the analytical model for } \\
\text { the calculation of deflection } \\
\text { D difference between the dynamic and static deflec- } \\
\text { tion (in \%) }\end{array}$} & $w_{\max . ~ s t}^{\mathrm{S}}$ & $\begin{array}{l}\text { maximum static deflection of the beam calcu- } \\
\text { lated by the first-order shear deformation lami- }\end{array}$ \\
\hline & $W_{\mathrm{m}}(\xi)$ & \\
\hline $\begin{array}{l}\text { Ds difference between the static and dynamic } \\
\text { strength (in \%) }\end{array}$ & & $\begin{array}{l}\text { longitudinal coordinate of a cross-section of the } \\
\text { beam }(\mathrm{m})\end{array}$ \\
\hline \multirow{2}{*}{$\begin{array}{l}d_{11} \quad \text { element } 11 \text { of the laminate bending compliance } \\
\text { matrix }(1 / \mathrm{N} \mathrm{m})\end{array}$} & $X$ & lamina longitudinal tensile strength $(\mathrm{MPa})$ \\
\hline & $\mathrm{Y}$ & lamina longitudinal \\
\hline \multicolumn{2}{|l|}{ deflection ratio } & \\
\hline \multirow{2}{*}{$\begin{array}{ll}E_{\mathrm{f}} & \text { effective flexural modulus of the beam }(\mathrm{GPa}) \\
E_{1} & \text { lamina longitudinal modulus }(\mathrm{GPa})\end{array}$} & $Y$ & lamina transverse tensile strength $(\mathrm{MPa})$ \\
\hline & $Y_{\mathrm{c}}$ & lamina transverse compressive strength \\
\hline & & \\
\hline \multirow{3}{*}{$\begin{array}{ll}F & \text { static load in the analytical model }(\mathrm{N}) \\
F(t) & \text { dynamic load in the analytical model }(\mathrm{N}) \\
F / \delta & \text { slope of the load deflection curve obtained from } \\
& \text { an experimental test }(\mathrm{N} / \mathrm{m})\end{array}$} & $z$ & distance from neutral surface defined by the $x y$ \\
\hline & & \\
\hline & $Z$ & nar te \\
\hline \multirow{3}{*}{$\begin{array}{ll}\text { FR frequency ratio } \\
G_{\mathrm{f}} \\
\text { effective interlaminar shear modulus of the beam } \\
(\mathrm{GPa})\end{array}$} & & dimensionless longitudinal coordinate of the \\
\hline & & \\
\hline & 1 & majc \\
\hline \multirow{6}{*}{$\begin{array}{ll}G_{12} & \text { lamina shear modulus in plane } 12(\mathrm{GPa}) \\
G_{13} & \text { lamina shear modulus in plane } 13(\mathrm{GPa}) \\
G_{23} & \text { lamina shear modulus in plane } 23(\mathrm{GPa}) \\
H & \text { laminate thickness }(\mathrm{m}) \\
I_{y} & \text { second moment of inertia of the beam cross-sec- } \\
& \text { tion about neutral } y \text {-axis }\left(\mathrm{m}^{4}\right)\end{array}$} & & 3 \\
\hline & & 23 \\
\hline & $\omega_{n}^{\mathrm{L}}$ & $n$th natural circular frequency of the beam ob- \\
\hline & & 1 model, computed by \\
\hline & & laminated theory $(\mathrm{rad} / \mathrm{s})$ \\
\hline & $\omega_{n}^{\mathrm{S}}$ & $n$-sime nat \\
\hline \multirow{3}{*}{$\begin{array}{ll}k & \text { shear factor of the beam cross-section } \\
L & \text { support span (m) } \\
S & \text { in-plane shear strength, plane } 12(\mathrm{MPa})\end{array}$} & & \\
\hline & & \\
\hline & & . \\
\hline \multirow{3}{*}{$\begin{array}{ll}\text { SR } & \text { stiffness ratio } \\
s_{11} & \text { longitudinal normal stress on the specimen, cal- } \\
& \text { culated by the numerical model (MPa) }\end{array}$} & $\Omega_{n}$ & circular frequency of the Fourier series of the \\
\hline & & load obtained in the experimental tes \\
\hline & $\phi_{x}$ & \\
\hline \multirow{2}{*}{$\begin{array}{ll}S_{13} & \text { interlaminar shear strength, plane } 13(\mathrm{MPa}) \\
t & \text { time }(\mathrm{s})\end{array}$} & & \\
\hline & $\sigma_{\mathrm{R}}$ & longitudinal laminate flexural strength (MPa) \\
\hline
\end{tabular}

The mechanical elements mentioned above may also be subjected to dynamic and impact loads, either in their service life or during assembly and maintenance operations. These are among the main factors that limit the use of the laminate materials [6], since the impact loads may originate damage that causes important changes in the behaviour of the structural component. Low velocity impacts are especially dangerous because the damage may not be visually detected and may cause reductions of up to $60 \%$ in the mechanical properties [7].
In the assessment of the results of dynamic tests at low velocity, it should be verified that the effects of the inertia forces can be ignored in the model. This simplifies the treatment of the test data, as the same equations can be used as in a static test. Some authors $[8,9]$ have concluded that in drop-weight tower tests, the composite materials behave in a quasi-static way, whereas other researchers [10] contend that this cannot be assured in certain situations. Thus, it is essential, before interpreting the test results, to verify that the use of the quasi-static formulation is appropriate. 
In this kind of test, a certain level of noise appears in the result signals that may mask the property to be measured, and therefore this noise should be separated from the real signal of the tested material. With an adequate design of the test, it is possible to reduce the noise level, but it cannot be completely eliminated given the dynamic nature of the problem. For an appropriate filtrate that does not eliminate information of the test, it is advisable to identify the origin of the noise in the signal. One source of this noise could be the vibration of the specimen and of the impactor during the test $[11,12]$. The identification is usually made by analytical or numerical models.

Less is known about the behaviour of the composite at low temperatures under dynamic conditions. Some authors have studied the influence of the temperature on the strainrate effects in these materials [13], and others have analysed the effects of temperature on the damage caused by impact on carbon reinforced plates at low [14] and high [15] impact velocities, as well as by temperature on the notched Izod impact resistance of pultruded glass fibre-reinforced beams [5].

In the design of mechanical and structural beam components, it is necessary to ascertain the way in which low temperature and bending moments under dynamic conditions influence the mechanical behaviour of laminate composites. The experimental tests used to analyse this behaviour are three- or four-point bending tests, although most researchers carry out these tests at room temperature. Bending tests present the advantage of simplicity as neither tabs nor grips are required and the specimen preparation is thus greatly simplified [16].

A bending test provides a record of the applied load and the mid-span deflection of the specimen. From this information, the flexural strength and the effective flexural modulus of the laminate may be calculated. Most researchers use the equations of the classical laminated theory. However, since composite laminates are considerably affected by shear stresses, it may be necessary to use models that consider these stresses. High-order shear theories have been developed [17 19] but usually the firstorder shear deformation laminate theory is found to be sufficiently accurate.

The present work analyses the flexural mechanical behaviour of carbon/epoxy laminate beam elements under dynamic conditions and at low temperatures. The conditions to which these materials may be subjected during their life in service were reproduced from quasi-static and dynamic three-point bending tests at three temperatures $\left(20^{\circ} \mathrm{C},-60^{\circ} \mathrm{C}\right.$ and $\left.-150{ }^{\circ} \mathrm{C}\right)$. The test parameters were defined and the test results interpreted by means of an analytical model and a numerical simulation, using the finite element method.

\section{Analysis of the dynamic bending test}

A theoretical study was made of the three laminates in order to select a specimen support span to minimize the shear forces in a three-point bending test. The beam tested was modelled by the classical laminated theory and the first-order shear deformation laminate theory. Different support spans were considered to ensure that the bending moments were preponderant over the shear forces, and therefore that failure occurred mainly from tensile-compression stresses.

For the calculated support span using the classical laminated theory, the possibility of neglecting the effects of inertia forces in the calculation of the different parameters of the problem was considered with a view to using the equations of the strength of materials.

The beam models were also used to determine the origin of the noise in the signal in the dynamic tests, which could mask the real behaviour of the beam. This noise was filtered by calculating the natural frequencies of the impactor and the test specimen.

The results were corroborated by a two-dimensional numerical model implemented in a finite element code, as explained below.

\subsection{Material}

Three laminate lay-ups were analysed: unidirectional (10 plies) and cross-ply $[0 / 90]_{3 \mathrm{~S}}$ laminates made from a prepreg AS4/3501-6 tape, and a plain woven laminate (10 plies) from a pre-peg AGP-193-PW/8552 fabric. All laminates were manufactured in autoclave by SACESA (Spain) from pre-preg of HEXCEL Composite Materials, following the normal manufacturing process and quality controls of the Aeronautical Industry. The material properties used in the analytical and numerical models were taken from data provided by the manufacturer, and from the bibliography [20,21], see Table 1 .

Table 1

Lamina properties

\begin{tabular}{llc}
\hline Properties & Tape lamina & Woven lamina \\
\hline Density $\left(\mathrm{kg} / \mathrm{m}^{3}\right)$ & 1582 & 1584 \\
Lamina thickness $(\mathrm{mm})$ & 0.20 & 0.22 \\
$E_{1}(\mathrm{GPa})$ & 118 & 60 \\
$E_{2}(\mathrm{GPa})$ & 10 & 60 \\
$G_{12}(\mathrm{GPa})$ & 6.20 & 5.28 \\
$G_{13}(\mathrm{GPa})$ & 6.20 & 5.28 \\
$G_{23}(\mathrm{GPa})$ & & 3.58 \\
$v_{21}$ & 0.280 & 0.046 \\
$v_{31}$ & & 0.320 \\
$v_{32}$ & 0.4 & 0.400 \\
$X(\mathrm{MPa})$ & 1930 & 771 \\
$X_{\mathrm{c}}(\mathrm{MPa})$ & 1390 & \\
$Y(\mathrm{MPa})$ & 45 & \\
$Y_{\mathrm{c}}(\mathrm{MPa})$ & 188 & \\
$Z(\mathrm{MPa})$ & & \\
$Z_{\mathrm{c}}(\mathrm{MPa})$ & & \\
$S(\mathrm{MPa})$ & 73 & \\
$S_{13}(\mathrm{MPa})$ & & \\
\hline
\end{tabular}



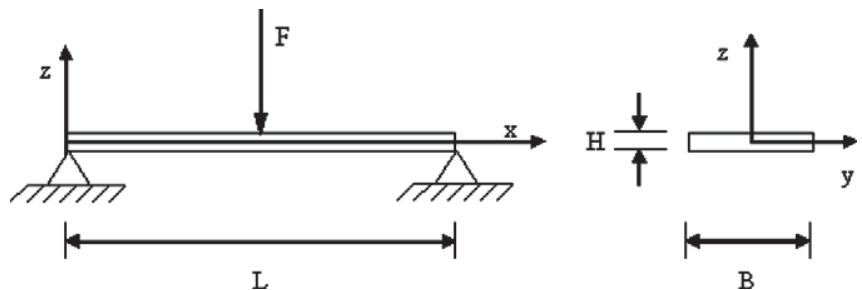

Fig. 1. Model used in the analytical study.

\subsection{Analytical model}

The specimen used in the tests was modelled as a simply supported beam of rectangular cross-section, subjected to a load applied in its mid-span, Fig. 1.

The maximum static deflection of the beam was determined as a function of the applied load, by classical laminated theory, neglecting interlaminar shear and Poisson effects. This problem is widely known [19,22] and leads to a solution that is compatible with the results from an isotropic material. The deflection is given by:

$w_{\max . s t}^{\mathrm{L}}=-\frac{d_{11} \cdot F \cdot L^{3}}{48 \cdot B}$

Eq. (1) is identical to that of the Euler Bernoulli beam theory of homogeneous isotropic materials, with the equivalence $\left\langle E_{\mathrm{f}} \cdot I\right\rangle=\frac{B}{d_{11}}$.

This deflection was also calculated by the first-order shear deformation laminate theory:

$w_{\max . s t .}^{\mathrm{S}}=-\frac{d_{11} \cdot F \cdot L^{3}}{48 \cdot B} \cdot\left(1+\left(\frac{12 \cdot a_{55}}{k \cdot H^{2} \cdot d_{11}}\right) \cdot\left(\frac{H}{L}\right)^{2}\right)$

which is equivalent to that of a Timoshenko beam if $\left\langle k \cdot A \cdot G_{\mathrm{f}}\right\rangle=\frac{k \cdot B}{a_{55}}$. In this study the shear factor used in an isotropic material, $k \quad 5 / 6$, was selected, as other authors have recommended [19].

The first step of the analytical dynamic study was to determine the natural frequencies of vibration of the specimens. From the Hamilton Principle, with the use of the kinematic hypotheses of the classical laminated theory and of the first-order shear deformation laminate theory, it is possible to obtain the differential equations to calculate the free oscillation of the beam [19]. Imposing the boundary and initial conditions of the problem (simply supported beam that starts from rest), the movement governing equations of the beam are:

- For the classical laminated theory, taking into account the inertial effect in the rotation.

$$
\begin{aligned}
& \frac{\partial^{2}}{\partial x^{2}}\left(\frac{1}{d_{11}} \cdot \frac{\partial^{2} w}{\partial x^{2}}\right)=I_{2} \cdot \frac{\partial^{4} w}{\partial x^{2} \partial t^{2}}-I_{0} \cdot \frac{\partial^{2} w}{\partial t^{2}} \\
& x=0\left\{\begin{array}{l}
w(0, t)=0 \\
\frac{d^{2} w(0, t)}{d x^{2}}=0
\end{array} \quad x=L\left\{\begin{array}{l}
w(L, t)=0 \\
\frac{d^{2} w(L, t)}{d x^{2}}=0
\end{array}\right.\right.
\end{aligned}
$$

- For the first-order shear deformation laminate theory:

$$
\begin{aligned}
& \frac{k}{a_{55}} \cdot\left(\frac{\partial \phi_{x}}{\partial x}-\frac{\partial^{2} w}{\partial x^{2}}\right)=I_{0} \cdot \frac{\partial^{2} w}{\partial t^{2}} \\
& \frac{1}{d_{11}} \cdot \frac{\partial^{2} \phi_{x}}{\partial t^{2}}-\frac{k}{a_{55}} \cdot\left(\phi_{x}-\frac{\partial w}{\partial x}\right)=I_{2} \cdot \frac{\partial^{2} \phi_{x}}{\partial t^{2}} \\
& x=0\left\{\begin{array}{l}
w(0, t)=0 \\
\frac{d \phi_{x}(0, t)}{d x}=0
\end{array} \quad x=L\left\{\begin{array}{l}
w(L, t)=0 \\
\frac{\mathrm{d} \phi_{x}(L, t)}{\mathrm{d} x}=0
\end{array}\right.\right.
\end{aligned}
$$

where $I_{0}=\int_{-\frac{H}{2}}^{\frac{H}{2}} \rho \cdot \mathrm{d} z$ and $I_{2}=\int_{-\frac{H}{2}}^{\frac{H}{2}} \rho \cdot z^{2} \mathrm{~d} z$

Using the classical laminated theory the natural frequencies of the beam are:

$\omega_{n}^{\mathrm{L}}=\frac{\left(\frac{n \cdot \pi}{L}\right)^{2}}{\sqrt{d_{11} \cdot I_{0} \cdot\left(1+\frac{I_{2}}{I_{0}} \cdot\left(\frac{n \cdot \pi}{L}\right)^{2}\right)}}$

afnd for the first-order shear deformation laminate theory:

$\omega_{n}^{S}=\left(\frac{n \cdot \pi}{L}\right)^{2} \cdot \sqrt{\frac{1}{I_{0} \cdot d_{11}}} \cdot \sqrt{1-\frac{\left(\frac{n \cdot \pi}{L}\right)^{2}}{\frac{k \cdot d_{11}}{a_{55}}+\left(\frac{n \cdot \pi}{L}\right)^{2}}}$

For simplicity, the dynamic deflection of the beam was analysed using only the classical laminated theory. Eq. (3) can be modified to incorporate the effect of an applied external load. After integrating, the beam deflection is:

$$
\begin{aligned}
w(\xi, t)= & \sum_{m}^{\infty}\left(C_{m} \cdot \operatorname{sen}\left(\omega_{m}^{\mathrm{L}} \cdot t\right)+D_{m} \cdot \cos \left(\omega_{m}^{\mathrm{L}} \cdot t\right)\right) \\
& +\sum_{m}^{\infty} \frac{W_{m}(\xi)}{\omega_{m}^{\mathrm{L}} \cdot \Lambda_{m} \cdot L} \cdot \int_{0}^{t} F(\tau) \cdot \operatorname{sen}\left(\omega_{m}^{\mathrm{L}} \cdot(t-\tau)\right) \cdot \mathrm{d} \tau
\end{aligned}
$$

where $\xi=\frac{x}{L}(0<\xi<1)$ and $\Lambda_{m}=\rho \cdot A \cdot \int_{0}^{1} W_{m}^{2}(\xi) \cdot \mathrm{d} \xi$

Assuming that, at the initial instant of time, no deformation of the beam exists and that the beam departs from rest, the integration constants are equal to zero $\left(\begin{array}{lll}C_{m} & D_{m} & 0\end{array}\right)$.

Using Eq. (9), the beam mid-span deflection is:

$w\left(\frac{1}{2}, t\right)=\sum_{m}^{\infty} \frac{2}{\rho \cdot A \cdot L \cdot \omega_{2 m-1}^{L}} \int_{0}^{t} F(\tau) \cdot \operatorname{sen}\left(\omega_{2 m-1}^{L} \cdot(t-\tau)\right) \cdot \mathrm{d} \tau$

For each laminate, a typical experimental record, obtained in the three-point dynamic tests, was used as input of the load $F(\tau)$. The maximum static mid-span deflection of the beam may be calculated from Eq. (1) as a function of the applied load. For the calculation of the dynamic deflection, the integral appearing in Eq. (10) must be solved; a Fourier series was used to represent the load mathematically, and therefore the integration could be carried out analytically:

$F(t)=A_{0}+\sum_{n=1}\left(A_{n} \cdot \cos \left(\Omega_{n} \cdot t\right)+B_{n} \cdot \operatorname{sen}\left(\Omega_{n} \cdot t\right)\right)$ 
With the use of the above Fourier series, Eq. (10) can be expressed in a closed form:

$$
\begin{aligned}
w\left(\frac{1}{2}, t\right)= & \sum_{m}^{\infty} \frac{2 \cdot A_{0}}{\rho \cdot A \cdot L \cdot \omega_{2 m-1}^{\mathrm{L}}{ }^{2}}\left[1-\cos \left(\omega_{2 m-1}^{\mathrm{L}} \cdot t\right)\right] \\
& +\sum_{n}^{\infty} \sum_{n 1}^{\infty} \frac{2 \cdot A_{n}}{\rho \cdot A \cdot L \cdot\left(\Omega_{n}^{2}-\omega_{2 m-1}^{\mathrm{L}}{ }^{2}\right)} \\
& \cdot\left[\cos \left(\omega_{2 m-1}^{\mathrm{L}} \cdot t\right)-\cos \left(\Omega_{n} \cdot t\right)\right] \\
& +\sum_{n}^{\infty} \sum_{n 1}^{\infty} \frac{2 \cdot B_{n}}{\rho \cdot A \cdot L \cdot \omega_{2 m-1}^{\mathrm{L}} \cdot\left(\Omega_{n}^{2}-\omega_{2 m-1}^{\mathrm{L}}{ }^{2}\right)} \\
& \cdot\left[\Omega_{n} \cdot \operatorname{sen}\left(\omega_{2 m-1}^{\mathrm{L}} \cdot t\right)-\omega_{2 m-1}^{\mathrm{L}} \cdot \operatorname{sen}\left(\Omega_{n} \cdot t\right)\right]
\end{aligned}
$$

The coefficients of the Fourier series were calculated from the discrete Fourier transform of the record of the experimental load. An algorithm for this transformation [23] was programmed, and for the analysis, the first 10 terms of the Fourier series were used because they were found to be sufficient for an accurate approximation to the value of the load.

\subsection{Numerical model}

A two-dimensional numerical model of a three-point bending test of the unidirectional laminate was used, since it gives a sufficiently accurate solution at lower computational cost than one of three dimensions.

The simulation was made with the finite element computer code ABAQUS, and given the symmetry of the problem, only half of the impactor, specimen and support system were modelled. The geometry of the specimen, the impactor and the support system were the same as in the experimental bending test. The impactor model included most of its details so as to calculate its natural frequencies of vibration (Fig. 2). The impactor and the supports are made of steel, and it was assumed that both exhibit an elastic lineal behaviour.

The specimen was discretized by two-dimensional elements of four nodes and the impactor by two-dimensional elements of three and four nodes. The three-node elements were used in the impactor tip where the mesh was refined due to the existing high stress and strain gradients in this zone. The mesh included a total of 5427 elements, 920 elements for the specimen and 5427 elements for the impactor. Additional computations were performed with various mesh refinements to verify convergence and accuracy.

\subsection{Results of the theoretical study}

\subsubsection{Selection of support span of the beam}

For the evaluation of the effect of shear stresses, the fundamental frequency and the maximum deflection were compared, calculated by the classical laminated theory and the first-order shear deformation laminate theory. Two dimensionless parameters, the frequency ratio (FR) and the deflection ratio (DR), were defined as

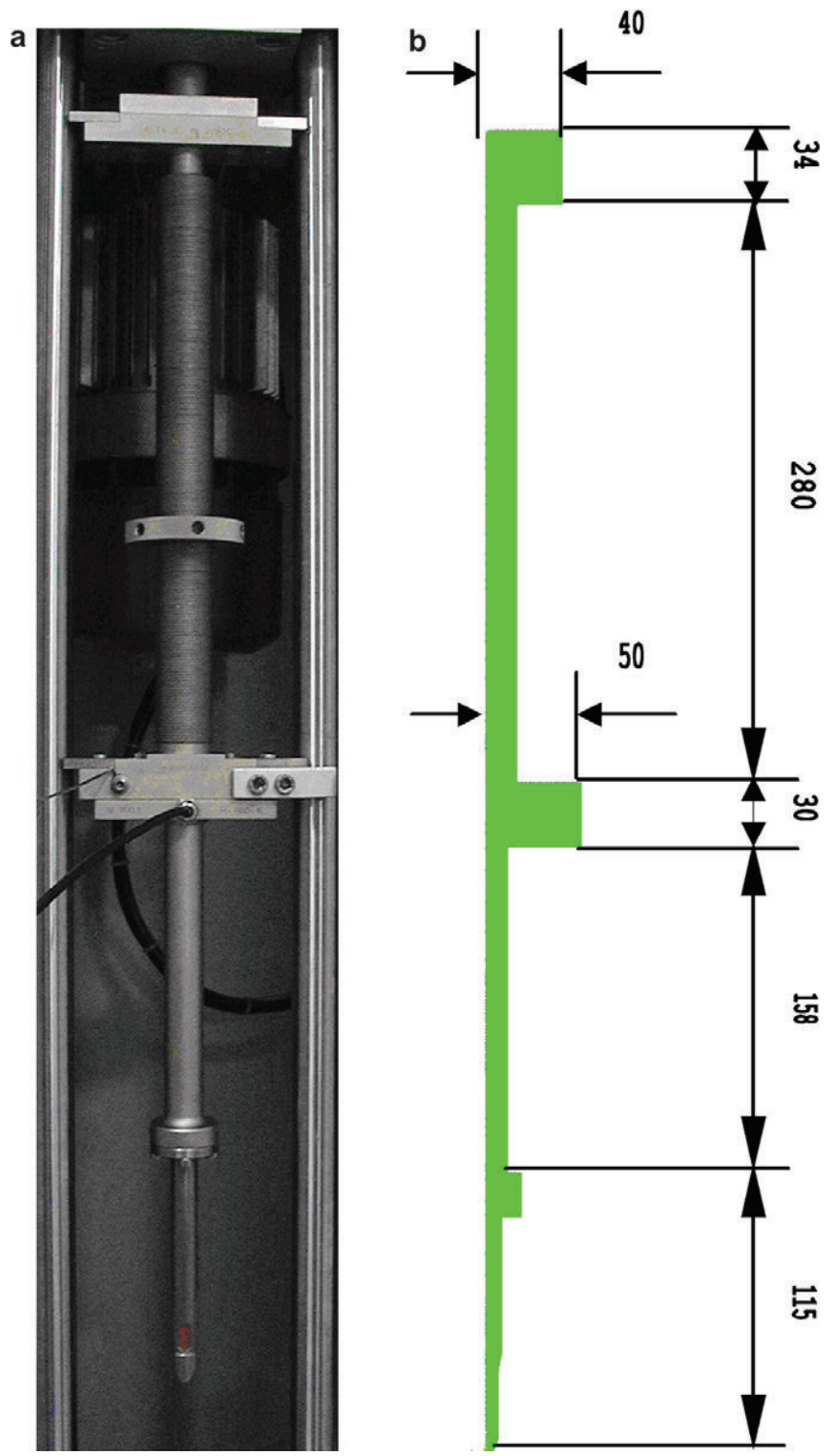

Fig. 2. Geometry of the impactor. (a) Experimental device. (b) Model used in the numerical simulation. Dimensions in $\mathrm{mm}$.

$\mathrm{FR}=\frac{\omega_{1}^{\mathrm{S}}}{\omega_{1}^{\mathrm{L}}}$
$\mathrm{DR}=\frac{w_{\max . \mathrm{st}}^{\mathrm{S}}}{w_{\max . \mathrm{st}}^{\mathrm{L}}}$

This analysis was made for different support span/thickness ratios $(L / H)$ and different stiffness ratios $(\mathrm{SR})$ of the specimen. The latter is defined as the relationship between the interlaminar shear stiffness and the bending stiffness of the material, expressed as

$\mathrm{SR}=\frac{H^{2} \cdot d_{11}}{12 \cdot a_{55}}$

For an isotropic material, SR is approximately 0.4. The values of the SR parameter for the considered laminates are shown in Table 2. 
Table 2

Stiffness ratios (SR) of the different laminates

\begin{tabular}{llll}
\hline & Unidirectional laminate & Cross ply laminate & Woven laminate \\
\hline$S R$ & 0.053 & 0.079 & 0.088 \\
\hline
\end{tabular}

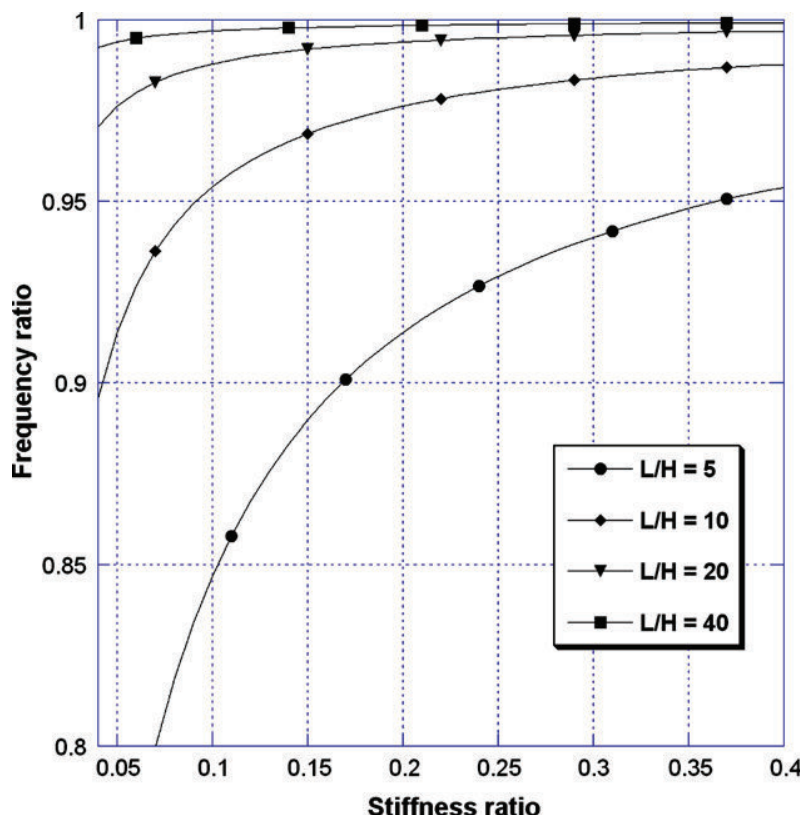

Fig. 3. Frequency ratio (FR) versus stiffness ratio (SR).

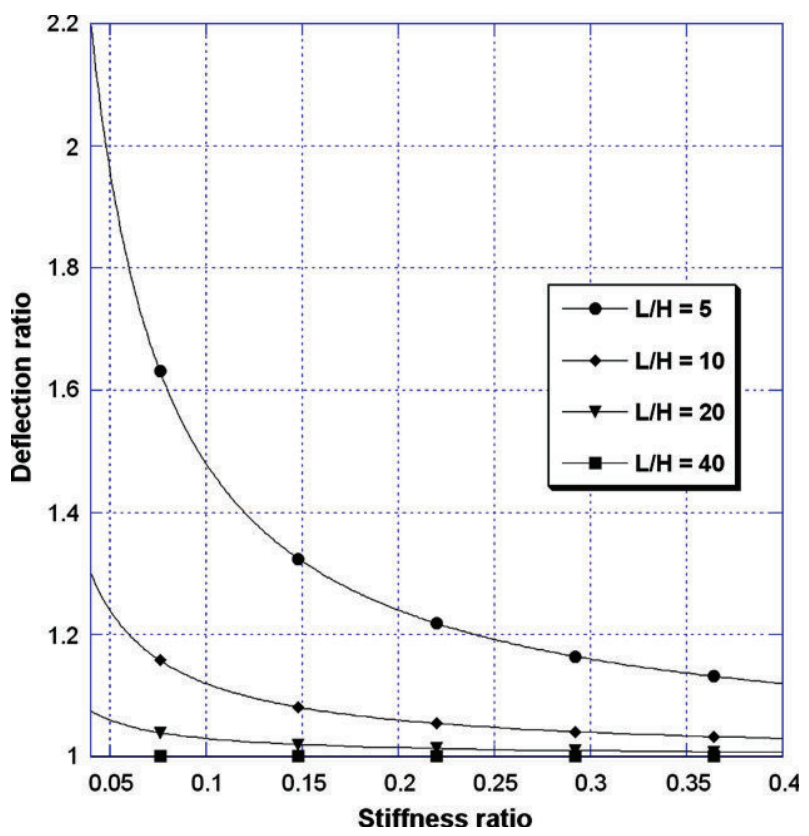

Fig. 4. Deflection ratio (DR) versus stiffness ratio (SR).

Table 3

Frequency ratio (FR) and deflection ratio (DR) of the different laminates with a support span of $80 \mathrm{~mm}$

\begin{tabular}{llll}
\hline Laminate & $\begin{array}{l}\text { Unidirectional } \\
\text { laminate }\end{array}$ & $\begin{array}{l}\text { Cross ply } \\
\text { laminate }\end{array}$ & $\begin{array}{l}\text { Woven } \\
\text { laminate }\end{array}$ \\
\hline FR & 0.9942 & 0.9943 & 0.9958 \\
DR & 1.0143 & 1.0136 & 1.0103 \\
\hline
\end{tabular}

Figs. 3 and 4 show the variation of the parameters FR and DR with SR and $L / H$. When the values of SR and $L / H$ increase, both the FR and the DR parameters approach unity. This implies that the shear effects are much less than those due to bending. In high anisotropic laminates with low SR parameter, longer support spans are required in order to neglect shear effects and to ensure that beam flexural behaviour is dominant.

After Figs. 3 and 4 were analysed, and given the stiffness ratio of the laminates used in this study, it was decided that the $L / H$ ratio should be close to 40 so that the shear effects are insignificant. Taking into account the laminates thicknesses considered in this study, a support span of $80 \mathrm{~mm}$ was selected.

The values of the frequency ratio and deflection ratio of the laminates with a support span of $80 \mathrm{~mm}$ are given in Table 3; the values of these parameters are very close to unity.

\subsubsection{Origin of the noise in the load-time record}

The first 10 natural frequencies of the different laminate beams were determined by the analytical model (Table 4). These values in the unidirectional and crossply laminates are similar, and are higher than those of the woven laminate. The natural frequencies of the

Table 4

Natural frequencies of the different laminates obtained by the analytical model

\begin{tabular}{rccc}
\hline & Natural frequencies $(\mathrm{Hz})$ & \\
\cline { 2 - 4 } & Unidirectional laminate & Cross ply laminate & Woven laminate \\
\hline 1 & 1233 & 1199 & 946 \\
2 & 4928 & 4792 & 3783 \\
3 & 11,075 & 10,763 & 8499 \\
4 & 19,656 & 19,090 & 15,081 \\
5 & 30,648 & 29,737 & 23,506 \\
6 & 44,020 & 42,665 & 33,748 \\
7 & 59,735 & 57,822 & 45,775 \\
8 & 77,752 & 75,151 & 59,549 \\
9 & 98,023 & 94,589 & 75,028 \\
10 & 120,495 & 116,066 & 92,167 \\
\hline
\end{tabular}

Table 5

Natural frequencies of the impactor and the unidirectional laminate specimen, determined by the numerical model

\begin{tabular}{rcc}
\hline & $\begin{array}{l}\text { Impactor natural } \\
\text { frequencies }(\mathrm{Hz})\end{array}$ & $\begin{array}{l}\text { Specimen natural } \\
\text { frequencies }(\mathrm{Hz})\end{array}$ \\
\hline 1 & 3903 & 1274 \\
2 & 6020 & 8384 \\
3 & 10,186 & 14,160 \\
4 & 11,921 & 28,350 \\
5 & 14,130 & 44,483 \\
6 & 17,866 & 46,254 \\
7 & 20,304 & 55,142 \\
8 & 22,191 & 69,233 \\
9 & 25,689 & 89,233 \\
10 & 27,821 & 106,029 \\
\hline
\end{tabular}



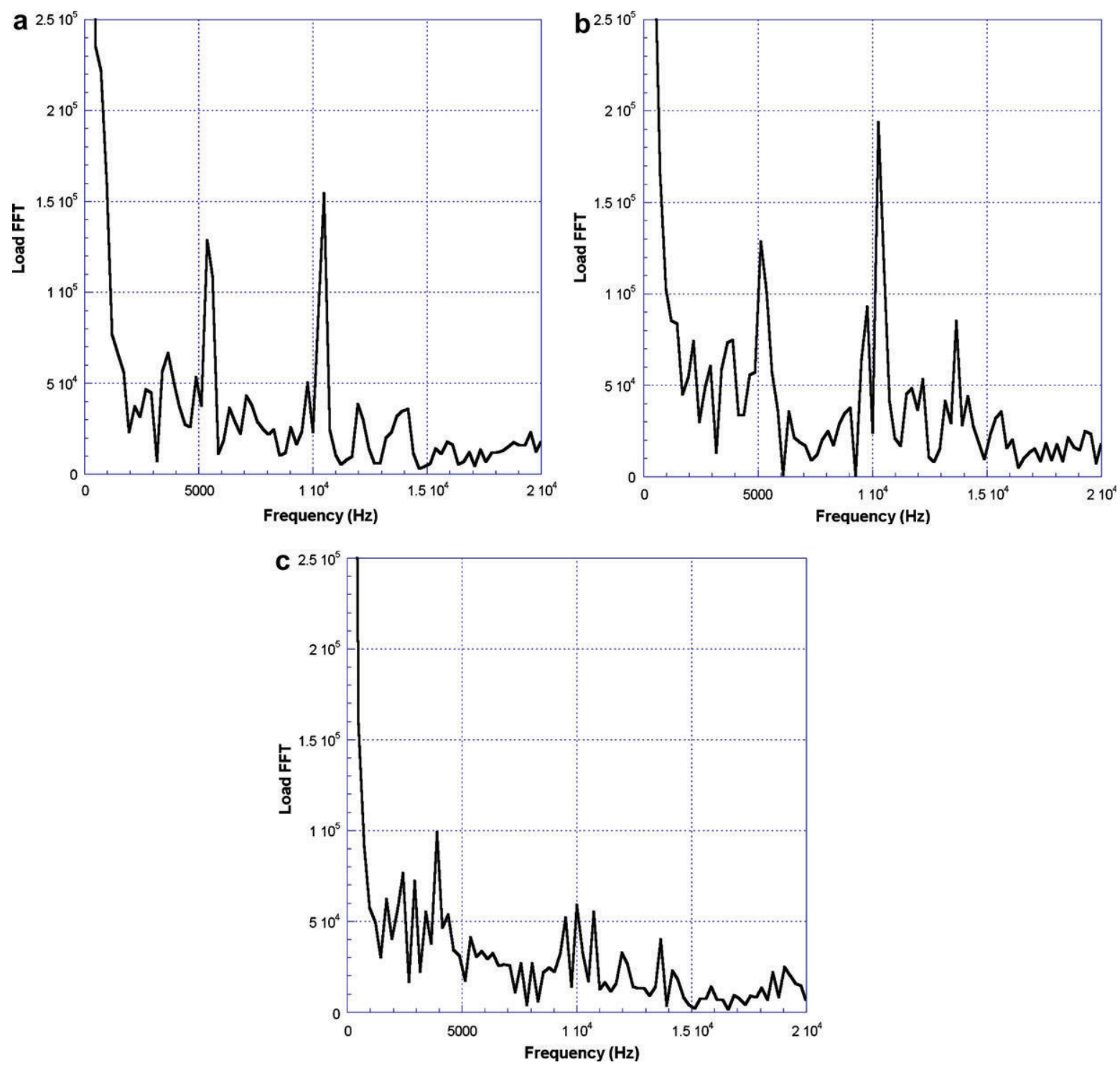

Fig. 5. Load spectra recorded in the tests (a) unidirectional laminate, (b) cross ply laminate, (c) woven laminate.

unidirectional laminate and impactor, determined from the numerical model, are shown in Table 5. The difference between the first natural frequency of the unidirectional laminate calculated with the analytical model and the numerical model is small. The other natural frequencies cannot be compared directly, since in the numerical model only the natural frequencies of the symmetrical bending modes of oscillation were calculated, because of the symmetry of the specimen-impactor model, and due to additional frequencies of other modes of oscillation appear (tensile-compression modes and mixed of tensile-compression and bending modes).

The oscillation frequencies of the noise in the experimental load record were determined by the load spectra of representative experimental (unidirectional, Fig. 5a; cross-ply, Fig. 5b, and woven laminates, Fig. 5c), using the fast Fourier transform [23]. All the curves have an initial zone in which it is difficult to derive accurate informa-

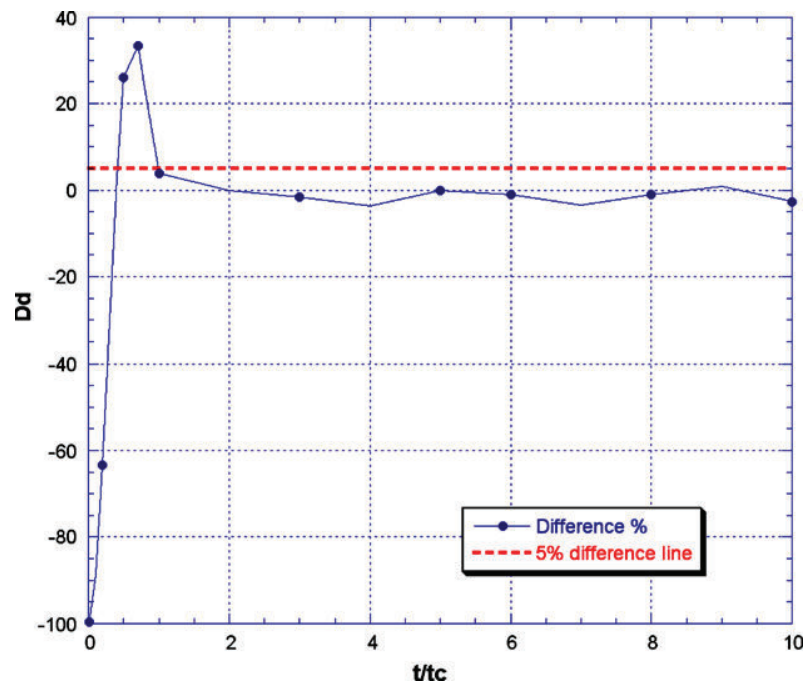

Fig. 6. Percentage differences between the static and dynamic deflections $(D d)$ of the unidirectional laminate and different test duration times divided by the natural period of vibration of the specimen. 
tion. Because the first natural frequency of the specimen, calculated by the analytical model, is within this zone in all the laminates studied, no conclusions could be drawn in such a zone.

After this zone, several peaks in all load spectra were close to the first frequencies of the beam, calculated by the analytical model, and the first frequencies of the impactor and the beam, determined from the numerical model.

The differences detected in the unidirectional and crossply laminate between beam natural frequencies and frequencies of the peaks of the load spectra may be due to the simplicity of the analytical model and to the estimation of the stiffness properties used. In the woven laminate the differences were more significant because its model (the same as that of the tape laminates) failed to take into account the reinforcement structure, which could alter its oscillatory response.

Both analytical and numerical simulations proved that several of the peaks in the load spectra of the experimental tests coincide with the natural frequencies of the impactor and beam, so that these frequencies could be eliminated, carrying out a filtrate of the load signal, without danger of eliminating information on the behaviour of the material.
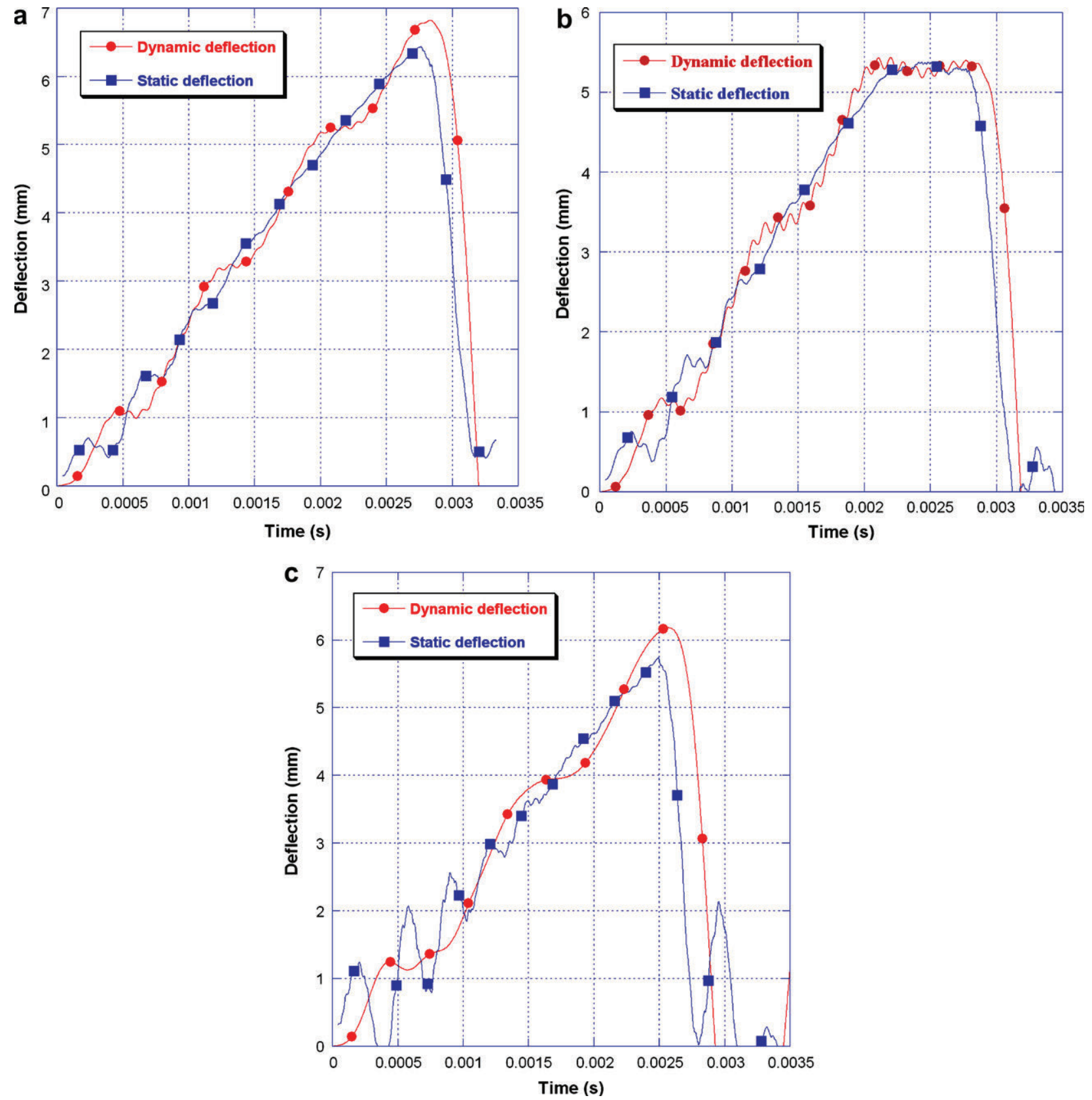

Fig. 7. Maximum deflections found in the analytical model. (a) Unidirectional laminate. (b) Cross ply laminate. (c) Woven laminate. 
2.4.3. Validation of the use of the quasi-static formulation In the study of the differences between the stresses and maximum deflection of the beam calculated by quasi-static equations and those calculated by equations that consider the inertia forces, a load of different time durations was applied to simulate the tests made at different impact velocities.
Fig. 6 shows the differences between the dynamic and the static deflection of the unidirectional laminate, which is similar in the other two laminates. In loads with a duration of more than 1.5 times the natural time of oscillation of the beam, the maximum deflection, considering the effect of the inertia forces by less than $5 \%$, differ from that calculated by equations from the strength of materials.
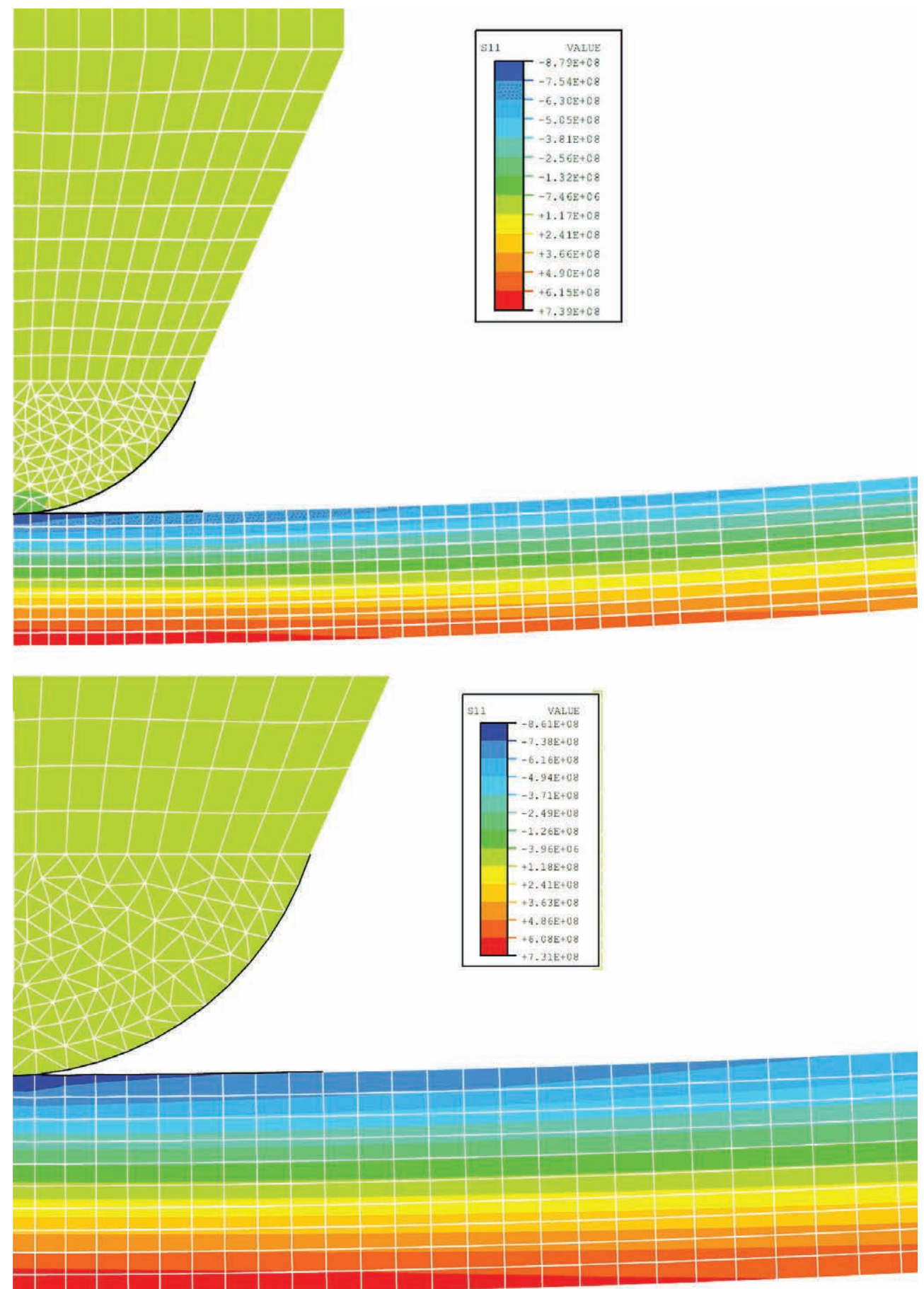

Fig. 8. Longitudinal stresses $\left(s_{11}\right)$ obtained in the simulation under dynamic conditions (top) and static conditions (bottom) when the mid span nodes of the specimen have moved $3.74 \mathrm{~mm}$ (in $\mathrm{MPa}$ ). 
The dynamic deflections calculated by the analytical model are no longer valid for very short times (below $4 \mu \mathrm{s}$, approximately) of the load duration, for which the effects of the propagation of the elastic waves should be considered. Under these conditions the response of the beam is not global and a different formulation is required.

An impact velocity similar to that of a fooling tool during a maintenance operation was adopted in the experimental tests; the total time at which the load is applied is approximately $2500 \mu \mathrm{s}$, which exceeds the limit previously mentioned.

The maximum deflection, as a function of the time up to the beam breaking, was calculated by the analytical model for a duration similar to that of the experimental tests. This deflection was computed by static equations and others that consider the inertia forces (Eqs. (1) and (12)). Fig. 7 shows that the maximum deflection in the dynamic tests may be estimated from the static equations for the three laminates.

In the numerical simulation, the stresses in the unidirectional specimen were also determined at different times, starting from the instant of impact. These stresses were compared with those determined in a static case and found to be similar for times longer than $0.5 \mu$ s from the beginning of the impact. Fig. 8 shows the longitudinal stresses $\left(s_{11}\right)$ in both cases at the instant at which the specimen has suffered a maximum deflection of $3.74 \mathrm{~mm}$, which corresponds to a time of $0.5 \mu \mathrm{s}$. This time is very short compared to that of time to failure (approximately $2500 \mu \mathrm{s})$, so that it is possible to use the static equations of the strength of materials to calculate the mechanical properties of laminates and the parameters of the tests in this work.

\section{Experimental procedure}

Static and dynamic three-point bending tests were carried out at three temperatures $\left(20^{\circ} \mathrm{C},-60{ }^{\circ} \mathrm{C}\right.$ and $-150^{\circ} \mathrm{C}$ ) on the three laminates described in Section 2. These temperatures may be considered representative of the working conditions of aeronautical and aerospace structures [15]: $20^{\circ} \mathrm{C}$ (room temperature), $-60{ }^{\circ} \mathrm{C}$ (temperature borne by an aircraft in flight) and $-150^{\circ} \mathrm{C}$ (temperature to which a spaceship or an artificial satellite in orbit is exposed).

Both in the static tests as well as in the dynamic ones, a climatic chamber was coupled to the testing machines to reach temperatures as low as $-150^{\circ} \mathrm{C}$ using liquid nitrogen. For the temperature measurement during the test, the thermostat of the climatic chambers and thermocouple placed close to the specimen were used.

The specimen cooling rate in the climatic chamber was estimated by a numerical simulation previously made by the same research group [24]. This study showed that once the test temperature is reached in the climatic chamber, an additional cooling time of the specimen is necessary to assure that the specimens attain a thermal balance with their environment. This time was 5 and $10 \mathrm{~min}$ at $-60{ }^{\circ} \mathrm{C}$ and $-150{ }^{\circ} \mathrm{C}$, respectively.

Rectangular specimens of $20 \mathrm{~mm} \times 105 \mathrm{~mm}$ were used, with a specimen support span of $80 \mathrm{~mm}$. This span was selected after the study indicated in Section 2.4.1, which showed that the interlaminar shear stresses were insignificant compared to the normal stresses generated by the bending moments.

Static tests were performed using an Instron universal testing machine with a load cell of $5 \mathrm{kN}$, coupled to an Instron climatic chamber. It was necessary to design and build a special three-point bending device to support low temperatures [25], to fulfil the requirements of ASTM D790 [26].

The load applied on the specimen and the deflection of the piston were recorded at every instant of the test. For an accurate measurement of the specimen mid-span deflection, an MTS longitudinal extensometer was adapted to the experimental device. This extensometer can work at temperatures between $65^{\circ} \mathrm{C}$ and $-269^{\circ} \mathrm{C}$. No extensometer gauges or LVDT extensometers were used because of the form of specimen failure, with a slough of fibres on the bottom face that would invalidate the deflection measured by these techniques.

Dynamic bending tests were performed in an instrumented drop weight tower (CEAST Fractovis) coupled to a climatic chamber. The load applied on the specimen was measured by the data acquisition software DAS4000. The impactor tip had a Charpy nose shape and its total mass was $3.6 \mathrm{~kg}$.

Since no standard for low temperature bending tests has been developed, a methodology based on the ASTM D790 Standard for three-point bending tests at room temperature under static conditions [26] was used.

Ten specimens were tested of each laminate and at each temperature, under static and dynamic conditions. Static

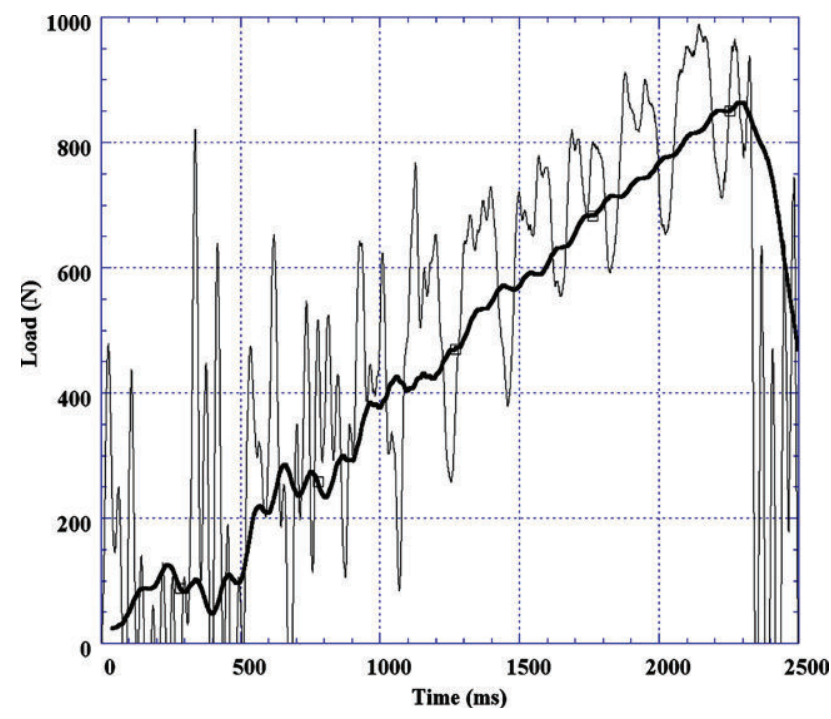

Fig. 9. Load time curve registered in a dynamic test of a cross ply laminate at $20^{\circ} \mathrm{C}$, filtered and without filtering. 
tests were performed at a strain rate of $10^{3} \mathrm{~min}{ }^{1}$, each providing a record of load-deflection. Dynamic tests were carried out using an impact energy of $30 \mathrm{~J}$, implying an impact velocity of $4.1 \mathrm{~m} / \mathrm{s}$. This energy was selected as equivalent to that of the drop of a tool during an assembly or maintenance operation. A record was made of the load that the impactor applies on the specimen at every instant of time. This recorded signal (see Fig. 9, as an example) presented a certain level of noise that masked the real response of the material and a filtrate was required to eliminate it, as indicated in Section 2.4.2. The oscillations at the beginning of the filtered curve could be due to inertial effects at the instant of contact between impactor and specimen.

From the filtered load time curve, assuming that there is a permanent contact between specimen and impactor, the deflection of their contact point was determined by successive integrations [12].
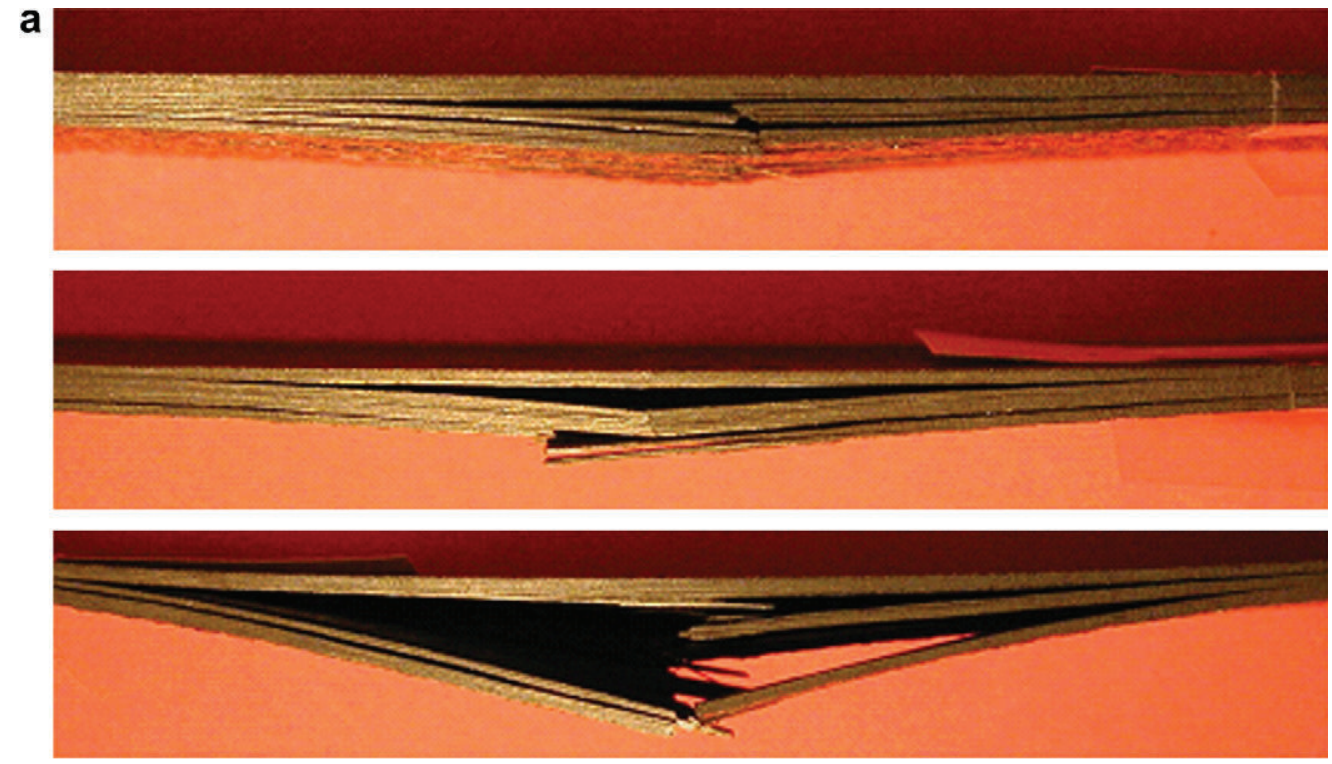

b
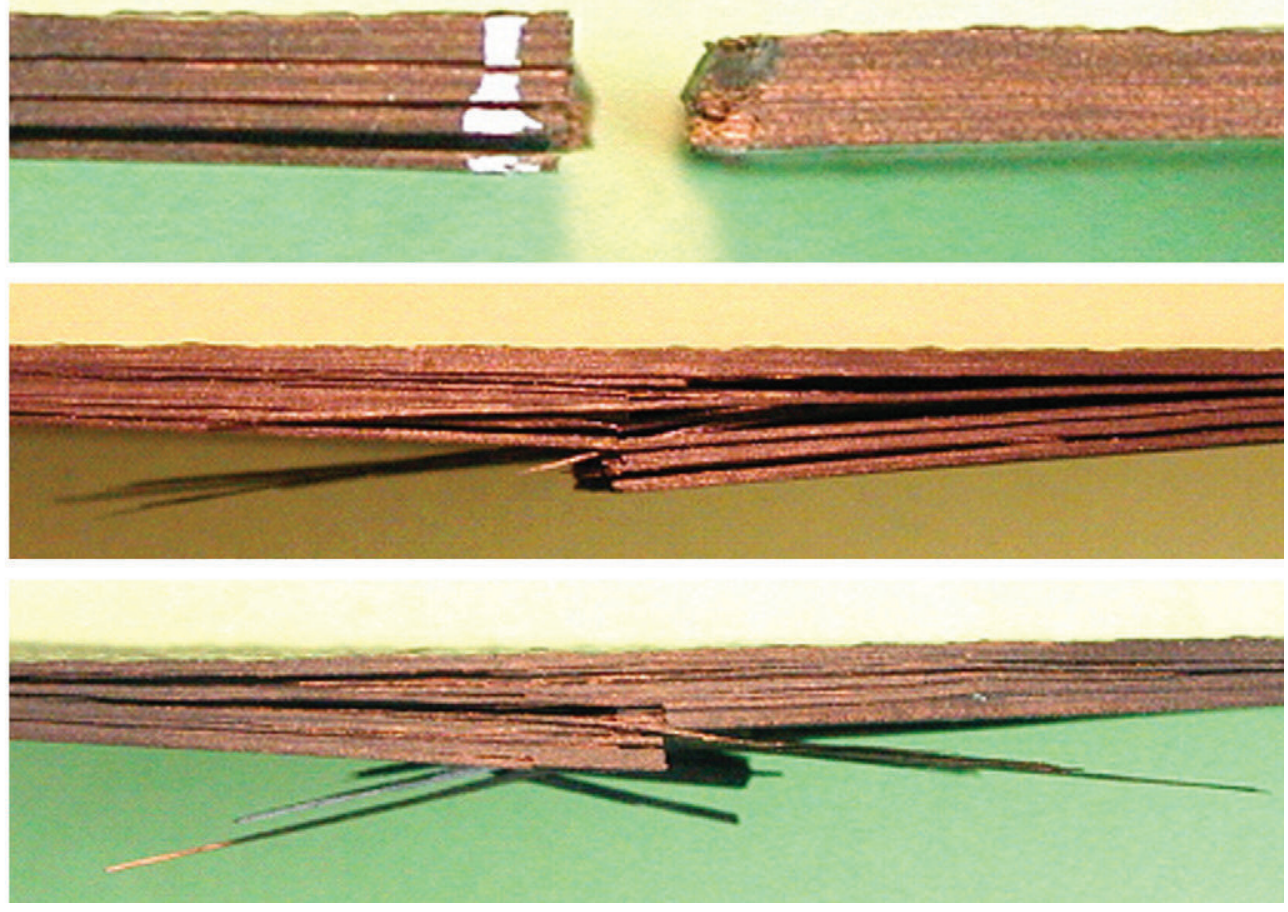

Fig. 10. Flexural failure mode in unidirectional laminate: (a) Under static conditions at $20^{\circ} \mathrm{C}$ (top), $60^{\circ} \mathrm{C}$ (centre) and $150{ }^{\circ} \mathrm{C}$ (bottom). (b) Under dynamic conditions at $20^{\circ} \mathrm{C}$ (top), $60^{\circ} \mathrm{C}$ (centre) and $150^{\circ} \mathrm{C}$ (bottom). 
By the use of the load deflection curve, under both static and dynamic conditions, the mechanical strength, $\sigma_{R}$, the effective flexural modulus, $E_{\mathrm{f}}$, and the absorbed energy up to failure, AE, were determined. The mechanical strength and the effective flexural modulus were determined using the equations of the classical laminated theory in static conditions, Eqs. (17) and (18)

$E_{\mathrm{f}}=\frac{1}{4} \cdot \frac{L^{3}}{B \cdot H^{3}} \cdot \frac{F}{\delta}$

$\sigma_{\mathrm{R}}=\frac{3}{2} \cdot \frac{F \cdot L}{B \cdot H^{2}}$

The absorbed energy was calculated using:
$\mathrm{AE}=\int_{0}^{t_{R}} F(t) \cdot d \delta(t)$

\section{Experimental results}

\subsection{Analysis of the failure mode}

The failure mode under static and dynamic conditions revealed that the main failure mechanism of the specimen in the different laminates was caused by tensile stresses of the plies on the surface opposite to the impact.

Approximately $55 \%$ of the specimens of unidirectional laminate tested under dynamic conditions at room
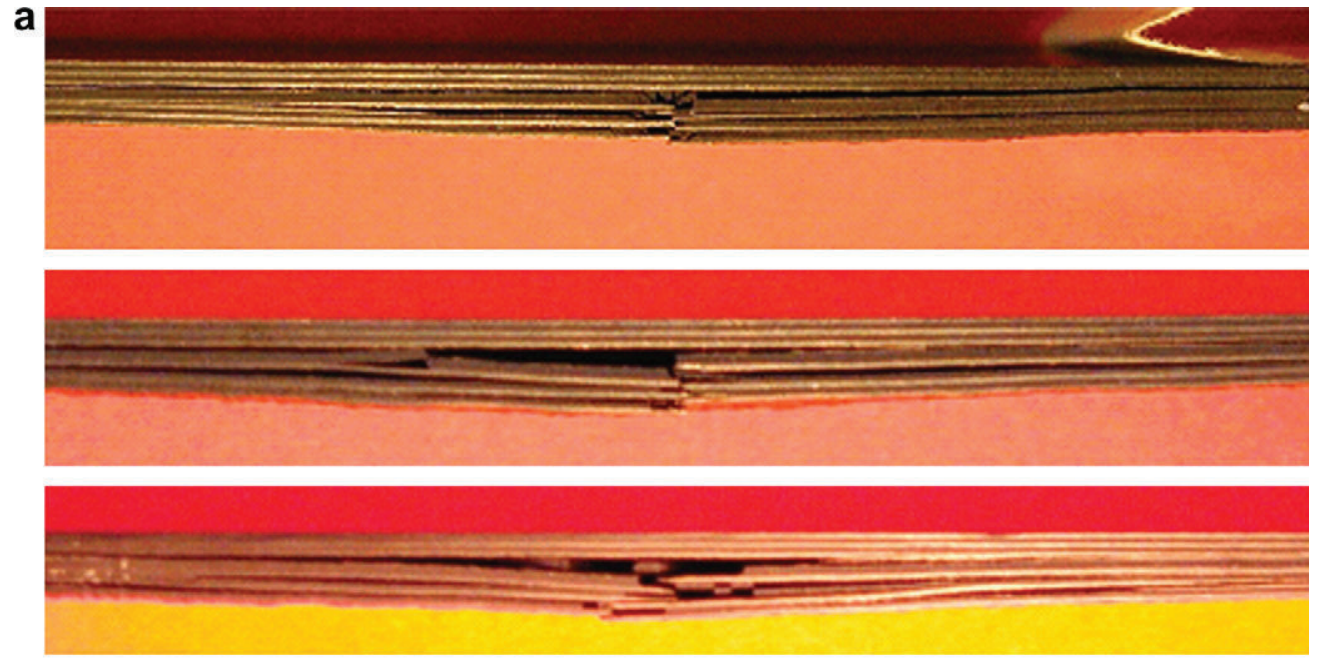

b
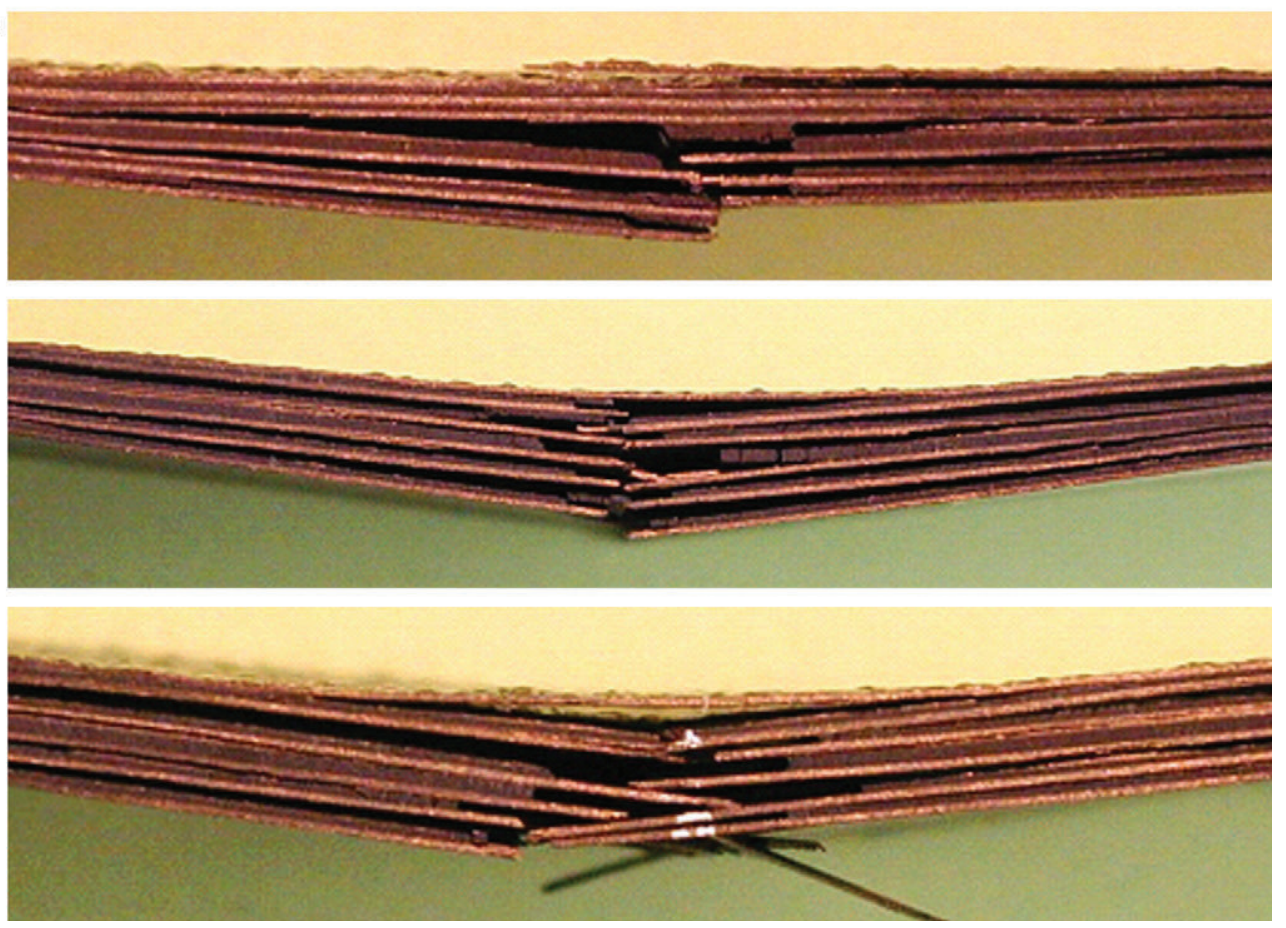

Fig. 11. Flexural failure mode in cross ply laminate: (a) Under static conditions at $20^{\circ} \mathrm{C}$ (top), $\quad 60^{\circ} \mathrm{C}$ (centre) and $150{ }^{\circ} \mathrm{C}$ (bottom). (b) Under dynamic conditions at $20^{\circ} \mathrm{C}$ (top), $60^{\circ} \mathrm{C}$ (centre) and $150^{\circ} \mathrm{C}$ (bottom). 
temperature suffered complete failure (Fig. 10). At low temperatures, some did not break (a greater number at $-60{ }^{\circ} \mathrm{C}$ than at $-150{ }^{\circ} \mathrm{C}$ ). Under dynamic conditions a slight fibre pull-out appeared at low temperatures, but under static conditions no fibre pull-out was appreciable at any of the test temperatures.

In the specimens of cross-ply laminate (Fig. 11) tested at room temperature, both in static and dynamic conditions, damage by compression occurred in the load area in the $0^{\circ}$ ply on the surface. This had been noticed by other researchers [27]. This phenomenon was found in $40 \%$ of the specimens tested under static conditions and 100\% of those tested under dynamic conditions.

None of the tests showed total failure of the laminate. The number of intact plies was greater in the static specimens than in those tested dynamically. Under static conditions, all the plies failed in the area subjected to tensile stresses, whereas under dynamic conditions, only the $0^{\circ}$ ply or the three plies $0^{\circ} / 90^{\circ} / 0^{\circ}$ nearest to the impact face remained intact. No fibre pull-out was observed at any of the test temperatures under static conditions, but this was noted in the dynamic tests at $-150^{\circ} \mathrm{C}$.
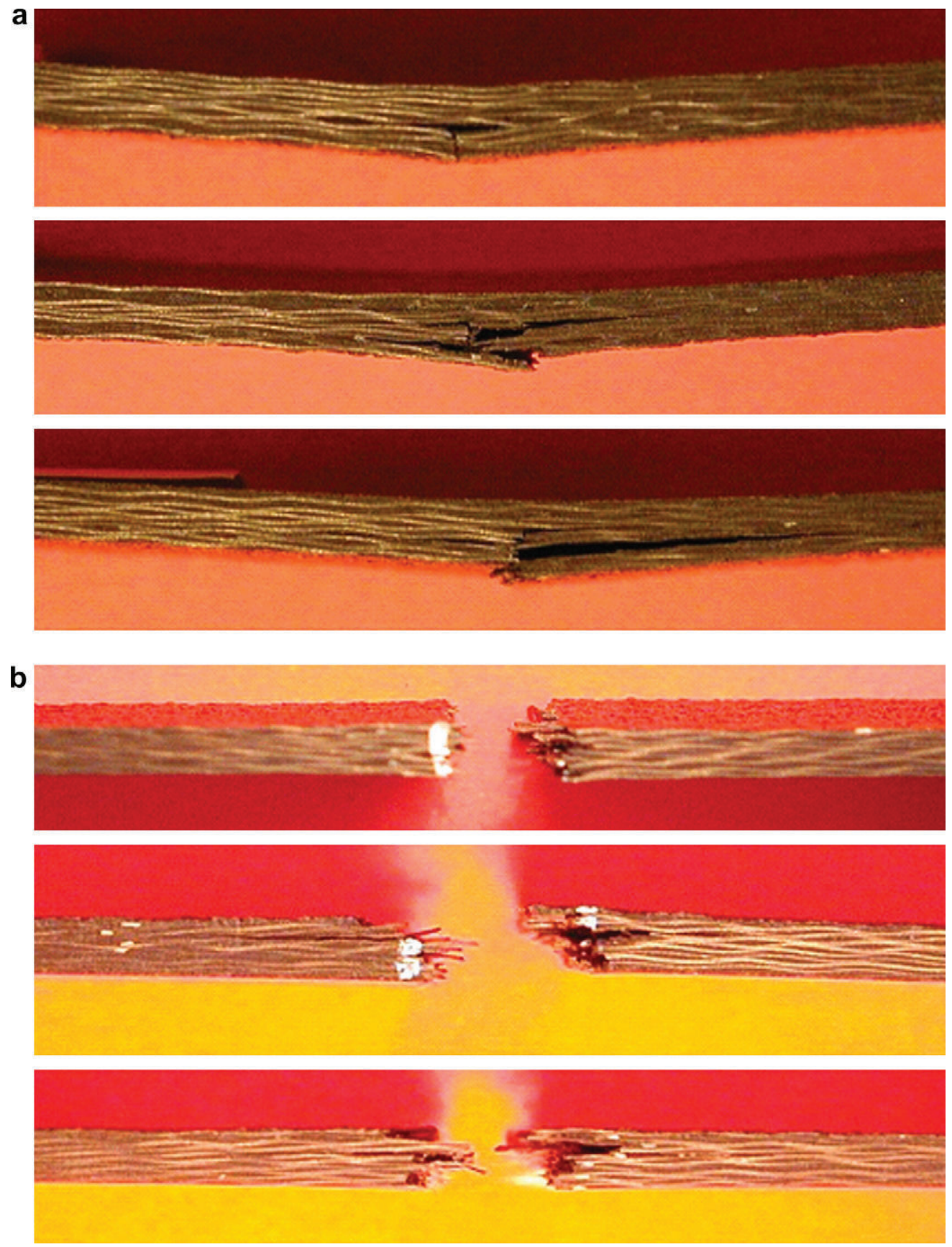

Fig. 12. Flexural failure mode in woven laminate: (a) Under static conditions at $20^{\circ} \mathrm{C}$ (top), $\quad 60^{\circ} \mathrm{C}$ (centre) and $150{ }^{\circ} \mathrm{C}$ (bottom). (b) Under dynamic conditions at $20^{\circ} \mathrm{C}$ (top), $60^{\circ} \mathrm{C}$ (centre) and $150^{\circ} \mathrm{C}$ (bottom). 
The delaminations were originated at the interfaces of the $0^{\circ}$ and $90^{\circ}$ plies at all temperatures, but not at the interfaces of the $90^{\circ}$ and $0^{\circ}$ plies, perhaps because of the greater flexural stiffness of the inferior $0^{\circ}$ ply. Delamination was encouraged by the change of fibre orientation of adjacent plies, this being more extensive when there was a wider relative angle between the plies, due to their differences in stiffness [28]. The greatest delaminations occurred with differences of angles of $90^{\circ}$, so that the cross-ply laminate underwent more delamination than the unidirectional laminate. The difference of flexural stiffness of the $0^{\circ}$ plies (maximum stiffness) and the $90^{\circ}$ plies (minimum stiffness) could explain the lower quantity of broken fibres in the $0^{\circ}$ direction, and the greatest amount in the $90^{\circ}$ plies.

In the woven laminate, a high percentage of specimens presented a total failure under dynamic conditions, this rate increasing as the temperature diminished: approximately $80 \%$ at $20{ }^{\circ} \mathrm{C}, 90 \%$ at $-60{ }^{\circ} \mathrm{C}$ and $100 \%$ at -150 ${ }^{\circ} \mathrm{C}$. Under static conditions this was not observed, although plies failed in the area subjected to tensile stress without fibre pull-out. The woven specimens tested under both static and dynamic conditions presented less delamination than the other laminates (Fig. 12), perhaps due to the greater interlaminar and intralaminar strength conferred by their reinforcement, preventing the propagation of delamination and shear cracks.

In all the laminates, the fall in temperature augmented delamination in the specimens. This is due to the fact that resin, the properties of which strongly determine delamination, becomes fragile at test temperatures $\left(-60^{\circ} \mathrm{C}\right.$ and $-150^{\circ} \mathrm{C}$ ) because these are below the vitreous temperature which is close to $-40^{\circ} \mathrm{C}$ in pure epoxy and $-45^{\circ} \mathrm{C}$ when charges are added [28 30].

\subsection{Analysis of mechanical properties}

The mean and the standard deviation of the flexural strength, effective flexural modulus and the absorbed energy were calculated for each laminate and temperature, both under static and dynamic conditions. The variation coefficient was lower than $8.5 \%$ on the flexural strength and effective modulus, this coefficient being $12 \%$ on the absorbed energy.

Flexural mechanical strength was lower under dynamic conditions than static in all the laminates. The temperature fall also decreased the mechanical strength, which is similar in the unidirectional and cross-ply laminates (the decrease was approximately $24 \%$ from $20{ }^{\circ} \mathrm{C}$ to $-150{ }^{\circ} \mathrm{C}$ under static conditions and $17 \%$ under dynamic conditions), and slightly less in woven laminate $(20 \%$ and $12 \%$, respectively) (Figs. 13 15). As expected, the unidirectional laminate showed higher flexure strength both at room temperature and at low temperatures, since the tensile stresses act in the direction of the fibres.

Static tensile tests at temperatures below $-60{ }^{\circ} \mathrm{C}$ on a cross-ply and a quasi-isotropic laminate carried out previ-

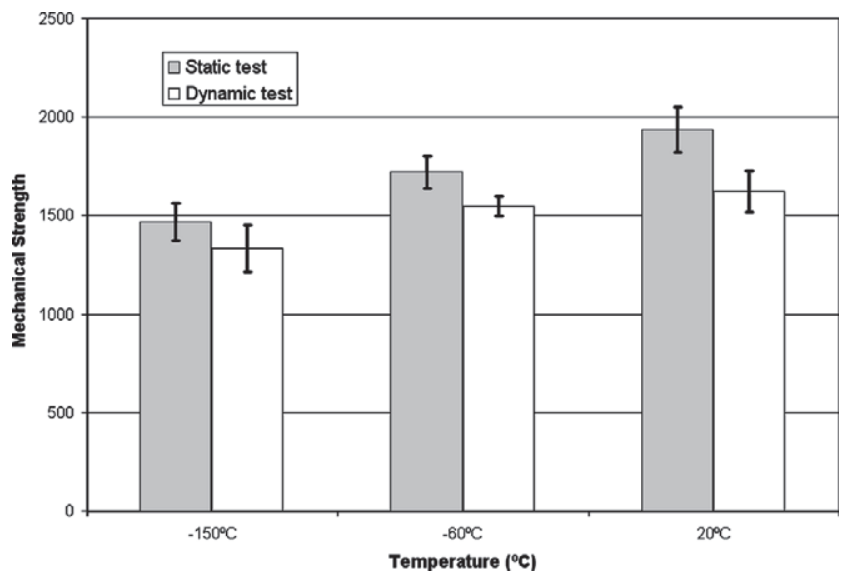

Fig. 13. Static and dynamic mechanical strength of the unidirectional laminate (in $\mathrm{MPa}$ ).

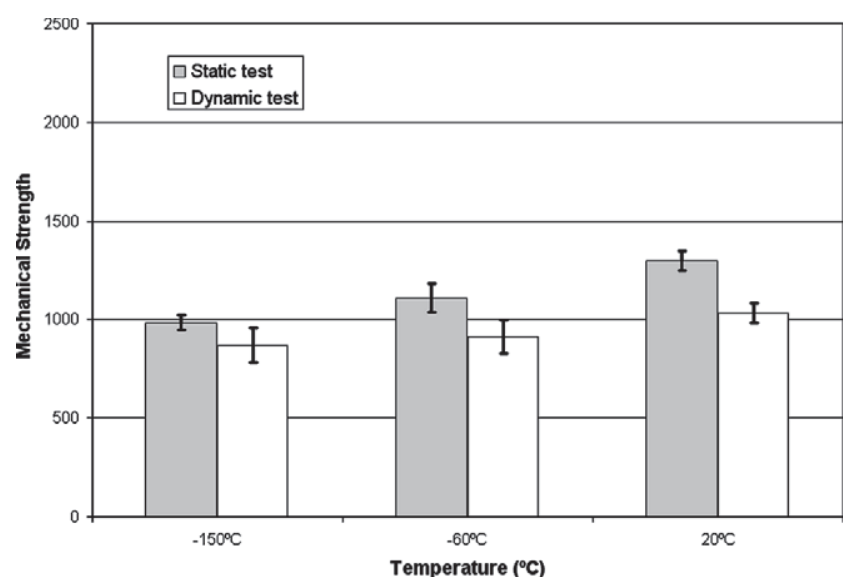

Fig. 14. Static and dynamic mechanical strength of the cross ply laminate (in $\mathrm{MPa}$ ).

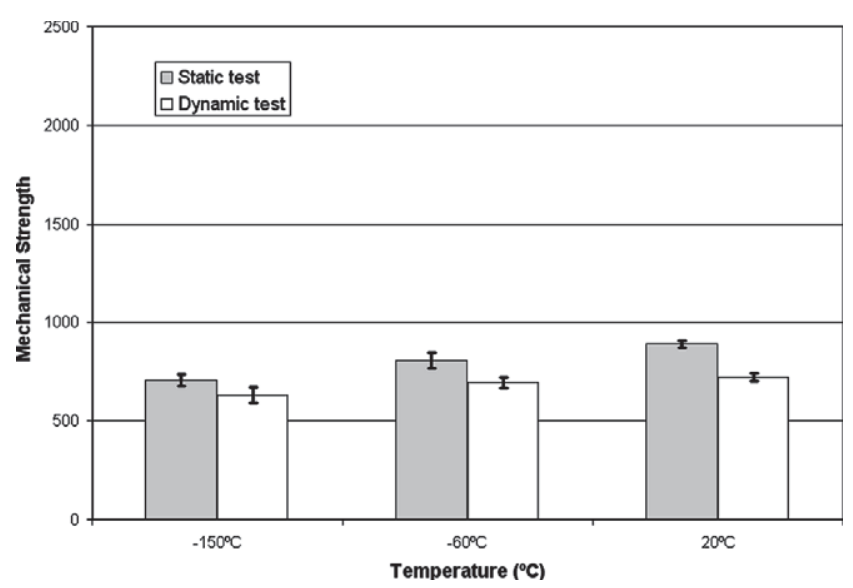

Fig. 15. Static and dynamic mechanical strength of the woven laminate (in $\mathrm{MPa})$.

ously by this research group [31] revealed that the tensile mechanical strength diminishes at lower temperatures. Scanning-electron microscopy showed this to be associated with a weakening of the fibre-resin union. Other 


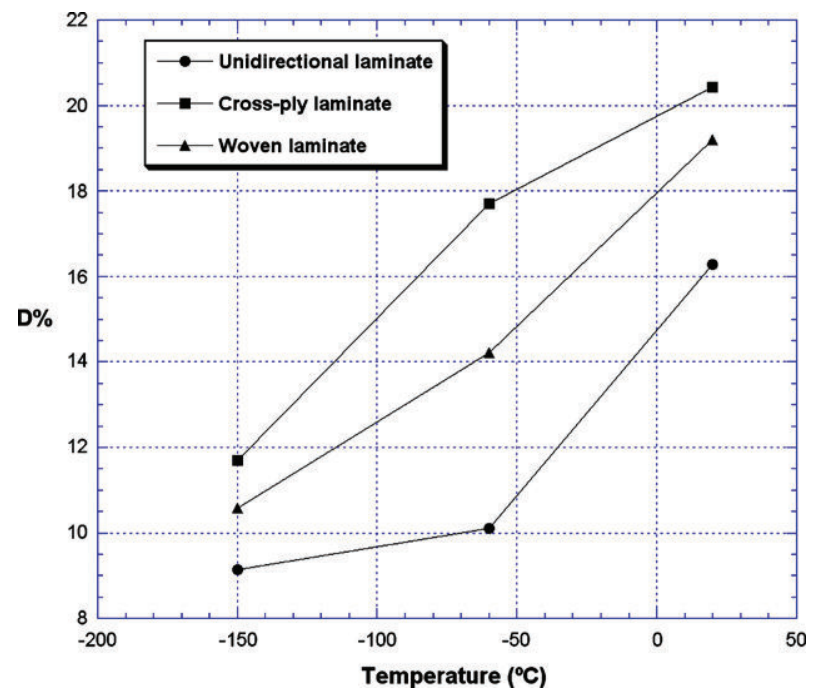

Fig. 16. Parameter $D$ versus temperature.

authors have found this reduction in materials of AS carbon fibres and epoxy resin under static conditions [3]. Since the main failure mechanism in the bending test was the tensile failure of the fibres on the lower face of the specimen, the mechanical strength lessened, both under static and dynamic conditions. Also, at lower temperatures more microdamage is expected because of the higher thermoelastic stress resulting from the thermalexpansion mismatches between fibres and matrix [32]. Under bending conditions the stress state becomes more complex than under tensile conditions, since compression and interlaminar shear stresses also arise in the specimen. The damage created in the resin could affect these stresses more than do the tensile stresses, controlled basically by the fibres that are less affected by temperature. Finally, at low temperature the matrix becomes brittle and does not allow relaxation of residual stress or stress concentrations [33].

Although the dynamic mechanical strength is lower than the static strength in all laminates and at all temperatures, this loss is smaller at low temperatures. In Fig. 16 this decrease is indicated by parameter $D$. For example, this parameter for the cross-ply laminate is approximately $20 \%$ at room temperature, and only $12 \%$ at $-150{ }^{\circ} \mathrm{C}$, perhaps because the resin is fragile at temperatures below its transition temperature, which may imply that its properties depend less on the strain rate.

Fig. 17 presents the variation of the effective flexural modulus of the different laminates with the temperature under static as well as dynamic conditions. In the crossply laminate the modulus remains practically constant, while in the other laminates it increases moderately at lower temperature (approximately 5\% at $-150{ }^{\circ} \mathrm{C}$ ). This could be associated with greater resin stiffness at lower temperature. The increase was probably moderated by the higher residual stress resulting from the different thermal expansion coefficients of the fibres and resin.

No accurate comparison could be made between the static and the dynamic effective flexural modulus because the deflections were measured by different techniques with different levels of accuracy. Fig. 17 shows a similar behaviour with temperature between the static and dynamic effective flexural moduli. At all temperatures, the unidirectional laminate presents the highest flexural modulus, and the woven laminate the lowest, in agreement with findings at room temperature by Padmanabhan and Kishore [34].

In all the laminates, as the temperature falls, the absorbed energy diminishes (Fig. 18). The effect of temperature on the energy is less in the woven laminate, with a reduction of $20 \%$ between $20^{\circ} \mathrm{C}$ and $-150{ }^{\circ} \mathrm{C}$, and more
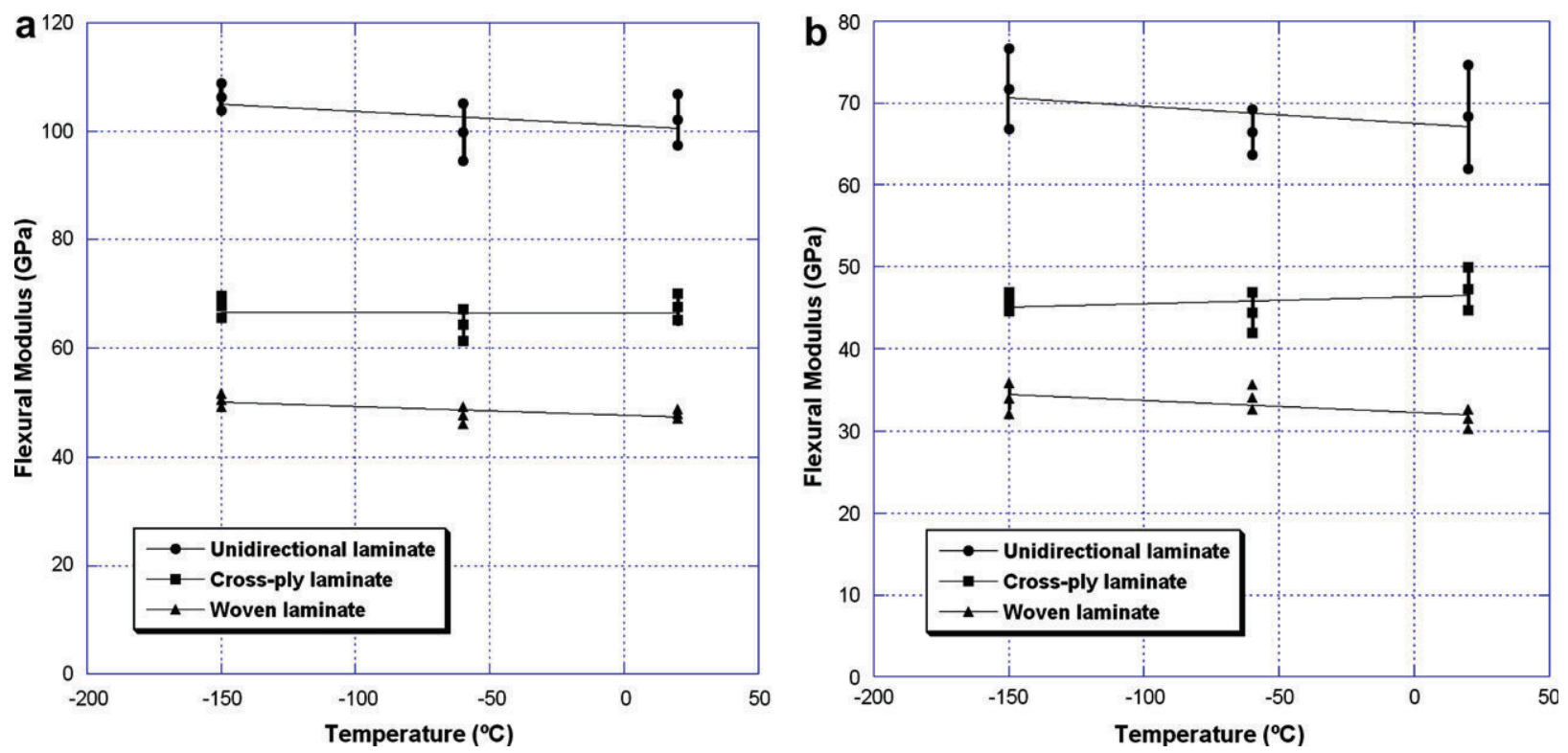

Fig. 17. Effective flexural modulus versus temperature. (a) Static tests. (b) Dynamic tests. 


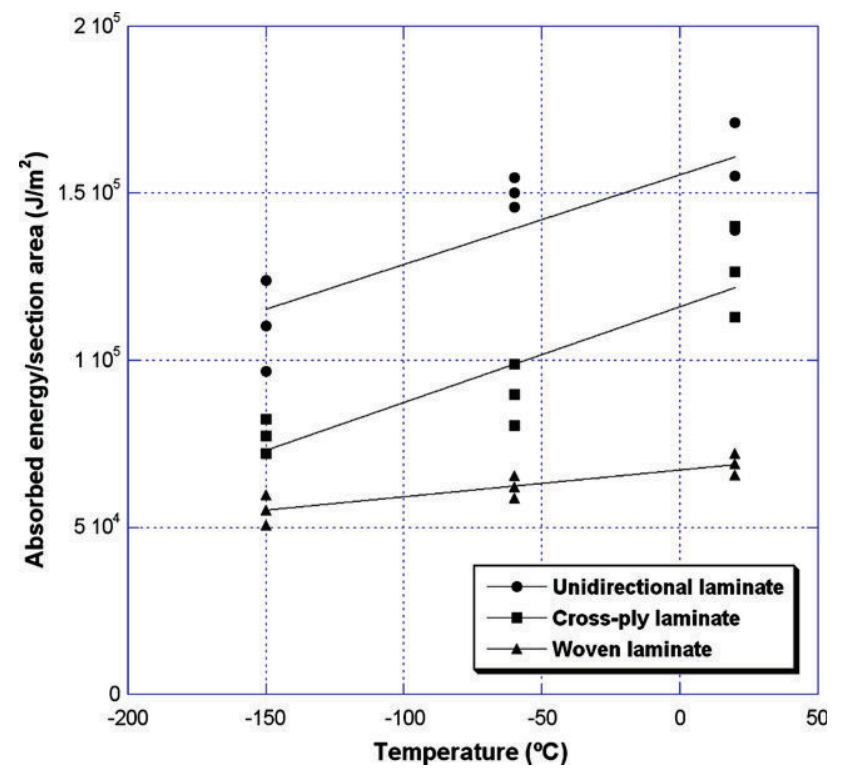

Fig. 18. Dynamic absorbed energy versus temperature.

in the cross-ply laminate, which registered a decrease of about $40 \%$. At all the temperatures, the absorbed energy until failure was greatest in the unidirectional laminate, followed by the cross-ply laminate and, lastly, the woven laminate. The weakest influence of temperature in the woven laminate could be due to the architecture of the reinforcement, whereas the properties of the resin, affected mainly by temperature, may exert greater control over the behaviour of the cross-ply laminate, as indicated above.

\section{Conclusions}

The main conclusions drawn from this study are:

- In the dynamic bending tests a previous model is needed to determine the equations that have to be used to interpret the results. It was demonstrated that under the experimental conditions in this study, it is possible to neglect the inertia forces and use the classical laminated theory under static conditions.

- The main failure mechanism of the laminates in bending tests is the breakage of fibres under tensile stress, on the surface opposite to the impact area. The failure mode, which varies in the different laminates, is affected by the temperature. In all cases the delamination increases at lower test temperatures .

- Mechanical strength was lower under dynamic conditions than under static conditions in all the laminates studied. The decrease differs in each laminate and is affected by the temperature. At lower temperatures, the differences between static and dynamic strength are smaller.

- The mechanical strength and the absorbed energy until failure diminish when the temperature falls, whereas the effective flexural modulus is hardly affected by the temperature, increasing slightly in the unidirectional and woven laminates and remaining practically constant in the cross-ply laminate.

\section{Acknowledgements}

The authors are indebted to the Spanish Comisión Interministerial de Ciencia y Tecnología (Project MAT-98/0273) for the financial support of this work.

\section{References}

[1] Morozov EV, Morozov KE, Selvarakalu V. Progressive damage modelling of SMC composite materials. Compos Struct 2003;62: 3616.

[2] Timmerman JF, Tillman MS, Hayes S, Seferis JC. Matrix and fiber influences on the cryogenic microcracking of carbon fiber/epoxy composites. Compos Part A Appl S 2002;33:323 9.

[3] Reed RP, Golda M. Cryogenic properties of unidirectional compos ites. Cryogenics 1995;34(11):909 28.

[4] Schutz JB. Properties of composite materials for cryogenic applica tions. Cryogenics 1998;38:3 12 .

[5] Kellogg KG, Kallmeyer AR, Dutta PK. Influence of moisture and reduced temperature thermal cycles on the Izod notch toughness of a pultruded glass fiber composite. Int $\mathrm{J}$ Offshore Polar 2003;13(3):232 9.

[6] Hawyes VJ, Curtis PT, Soutis C. Effect of impact damage on the compressive response of composite laminates. Compos Part A Appl S 2001;32(9):1263 70.

[7] Sanchez Saez S, Barbero E, Zaera R, Navarro C. Compression after impact of thin composite laminates. Compos Sci Technol 2005;65(13):19119.

[8] Sjoblom PO, Hartness JT, Cordell TM. On low velocity impact testing of composite materials. J Compos Mater 1988;22(1):30 52.

[9] Lee SM, Zahuta P. Instrumented impact and static indentation of composites. J Compos Mater 1991;25(2):204 22.

[10] Lifshitz JM, Gov F, Gandelsman M. Instrumented low velocity impact of CFRP beams. Int J Impact Eng 1995;16(2): 20115.

[11] Cheresh MC, McMichael S. Instrumented impact test data interpre tation. In: Kessler SL, Adams GC, Driscoll SB, Ireland DR, editors. Instrumented impact testing of plastics and composite materials. ASTM STP, vol. 936. Philadelphia: American Society for Testing and Materials; 1987. p. 923.

[12] Found MS, Howard A, Paran AP. Interpretation of signals from drop weight impact test. Compos Struct 1998;42:353 63 .

[13] Al Hassani STS, Kaddour AS. Strain rates effect on GRP, KRP and CFRP composite laminates. Key Eng Mater 1998;141 143: 42752.

[14] Karasek ML, Strait LH, Amateau MF, Runt JP. Effect of temper ature and moisture on the impact behaviour of graphite/epoxy composites: Part I Impact energy absorption. J Compos Tech Res 1995;17(1):3 10 .

[15] Im KH, Cha CS, Kim SK, Yang IY. Effect of temperature on impact damages in CFRP composite laminates. Compos Part B Eng 2001;32:669 82 .

[16] Kallel Kamoun I, Chateauminois A, Sidoroff F. Secondary effects in the analysis of the post buckling bending test. Compos Struct 2000;50:85 92.

[17] Levinson M. An accurate, simple theory of the statics and dynamics of elastic plates. Mech Res Commun 1980;7:343 50.

[18] Murthy MVV, An improved transverse shear deformation theory for laminated anisotropic plates, NASA TP 1903; 1981.

[19] Reddy JN. Mechanics of laminated composites plates. Florida (USA): CRC Press; 1997. 
[20] Soden PD, Hinton MJ, Kaddour AS. Lamina properties, lay up configurations and loading conditions for a range of fibre reinforced composite laminates. Compos Sci Technol 1998;58: 101122.

[21] McGowan DM, Ambur DR. Damage characteristics and residual strength of composite sandwich panels impacted with and without compression loading. In: 39th AIAA/ASME/ASCE/AHS/ASC struc tures, structural dynamics and materials conference, AIAA 981783 (CA, USA); 1998.

[22] Barbero EJ. Introduction to composite material design. Philadelphia (USA): Taylor and Francis; 1999.

[23] Press WH. Fortran numerical recipes. Cambidge (UK): Cambridge University Press; 1994.

[24] Gómez del Río T, Zaera R, Barbero E, Navarro C. Damage in CFRPs due to low velocity impact at low temperature. Compos Part B Eng 2005;36(1):41 50.

[25] Sánchez Sáez S. Comportamiento mecánico a flexión y tolerancia al dano de materiales de fibra de carbono y matriz epoxi a baja temperatura. PhD Thesis, University Carlos III of Madrid, Depart ment of Continuum Mechanics and Structural Analysis; 2002 [in Spanish].

[26] ASTM D790 98. Standard Test Methods for Flexural Properties of unreinforced and reinforced plastics and electrical insulating materi als. American Society of Testing and Materials. 1998
[27] Breikin NL, GurdalZ, Griffin OH.Compression of laminated composite beams with initial damage. J Reinf Plast Compos 1993;12:813 24

[28] Abrate S. Impact on composite structures. Cambidge (UK): Cam bridge University Press; 1998.

[29] Delaet M. Influences des vitesses de chargement et de la temperature sur l'endommagement et la resistance de composites croises verre/ époxyde. PhD Thesis, Ecole Nationale Supérieure d'Arts et Métiers, Centre de Bordeaux, 1995. [In French].

[30] Welsh LM, Harding J. Dynamic tensile response of unidirectionally reinforced carbon epoxy and glass epoxy composites. In: Proceedings of the 5th international conference on composite materials, San Diego (CA, USA); 1985. p. 151731.

[31] Sánchez Sáez S, Gómez del Río T, Barbero E, Zaera R, Navarro C. Static behavior of CFRPs at low temperatures. Compos Part B Eng 2002;33(5):383 90.

[32] Dutta PK. Flexural fatigue and fracture of unidirectional graphite/ epoxy composites at low temperatures. In: Proceeding of the 9th international conference on composite materials, Madrid, Spain; 1993. p. 86674.

[33] Hartwig G, Knaak S. Fibre epoxy composites at low temperatures. Cryogenics 1984;24:639 47.

[34] Padmanabhan K, Kishore S. Failure behaviour of carbon fibre/epoxy composites in pin ended buckling and bending test. Composites 1995;26(3):201 6 